ESTUDIO

\title{
FUNDAMENTOS DE LA PROPUESTA DE LA COMISIÓN FORO PENAL PARA LA PROTECCIÓN PENAL DEL MEDIO AMBIENTE
}

\author{
Jean Pierre Matus Acuña
}

En el presente artículo se desarrollan las ideas que sirvieron de fundamento a la propuesta de regulación de los delitos contra el medio ambiente preparada por la Secretaría Técnica de la Comisión Foro Penal, y que fueran acogidas prácticamente en su totalidad en el articulado del texto de Anteproyecto de Código Penal entregado al Presidente de la República el día 18 de diciembre de 2005. Estas ideas y articulado propuestos fueron elaborados, en una versión preliminar, en el marco del Proyecto Fondecyt 1010206-2001 sobre tratamiento penal de los delitos contra el medio ambiente en Chile, y ahora han sido también recogidos en un reciente Proyecto de Ley independiente de los Senadores Ávila, Girardi, Flores y Ominami (Boletín N 5614-12), actualmente en discusión en el Senado de la República.

Jean Pierre Matus A. Director del Centro de Estudios de Derecho Penal de la Universidad de Talca, Campus Santiago. Miembro de la Secretaría Técnica de la Comisión Foro Penal.

Véanse también en esta edición los artículos "Derecho Penal Medioambiental: ¿Porqué o cómo?”, de Roland Hefendehl, y “Comentario Crítico a la Regulación de los Delitos contra el Medio Ambiente en el Anteproyecto de Código Penal de 2005”, de Antonio Bascuñán R. (N. del E.)

Estudios Públicos, 110 (otoño 2008). 


\section{E}

n el presente texto se desarrollan las ideas que sirvieron de fundamento a la propuesta de regulación de los delitos contra el medio ambiente, preparada por la Secretaría Técnica de la Comisión Foro Penal, y que fueran acogidas prácticamente en su totalidad en el articulado del texto de Anteproyecto de Código Penal entregado al Presidente de la República el día 18 de diciembre de 2005. Estas ideas y articulado propuestos fueron elaborados, en una versión preliminar, en el marco del Proyecto Fondecyt 1010206-2001, sobre tratamiento penal de los delitos contra el medio ambiente en Chile, que dirigí en la Universidad de Talca, cuyos resultados se encuentran publicados en un texto de mi edición ${ }^{1}$. Para llegar a estas conclusiones se elaboraron durante el año 2001 diversos estudios de derecho comparado internacional ${ }^{2}$, los que se complementaron, durante el año 2002, con otras investigaciones sobre el derecho internacional y el nacional ${ }^{3}$. El resultado de estas investigaciones fue discutido entre los investigadores del proyecto y expertos extranjeros en el Seminario Internacional sobre Derecho Penal del Medio Ambiente, que se desarrolló en Talca y Pelluhue, en el mes de octubre de 2002, y en reuniones informales en enero de 2003 con

${ }^{1}$ Cfr. Matus, J. P. (ed.), Derecho Penal del Medio Ambiente, 2004. El informe final del que se extrajeron las ideas aquí reproducidas fue elaborado por J. P. Matus, María Cecilia Ramírez G., Marcelo Castillo y Marcos Orellana, todos investigadores de la Universidad de Talca.

${ }^{2}$ Los estudios referidos son los siguientes: “Acerca de la Existencia de Obligaciones Internacionales de Establecer Delitos Medioambientales, Contempladas en los Tratados Suscritos por la República de Chile”, de los profesores Jean Pierre Matus A. y Marcos Orellana C.; "Informe sobre la Protección Penal del Medio Ambiente en el Derecho Comparado de Tradición Continental”, de los profesores Jean Pierre Matus A., María Cecilia Ramírez G. y Marcelo Castillo; y "Derecho Penal Ambiental en la Tradición del Common Law”, del profesor Marcos Orellana C.

${ }^{3}$ En este período, bajo la dirección del profesor Jean Pierre Matus, se terminaron las memorias para obtener el grado de licenciado en ciencias jurídicas y sociales de la Universidad de Talca, “Obligaciones Internacionales de Establecer Delitos Medioambientales, Contempladas en los Tratados No Suscritos por Chile, Recopilación de Tratados Internacionales", de la alumna Marcia Allendes; y "Análisis de los Delitos de Carácter Ambiental Contenidos en el Código Penal y en las Leyes Especiales Chilenas”, de los alumnos Rodrigo Troncoso y Scarlett Quiroga. Además, en el Seminario Internacional sobre Derecho Penal del Medio Ambiente, organizado en el marco de este Proyecto Fondecyt, se presentaron las siguientes ponencias que en forma resumida se incorporan a este trabajo, de los profesores Álvarez Inma, Valeije: "Cuestiones Dogmáticas sobre el Delito de Contaminación Ambiental en el Artículo 325 del Código Penal Español”, Brandariz García, José Ángel: "Cuestiones Derivadas de la Concurrencia del Derecho Penal y del Derecho Administrativo en Materia de Tutela del Medio Ambiente”, Faraldo Cabana, Patricia: "Autoría Mediata con Aparatos Organizados de Poder en el Ámbito Empresarial”; y Puente Aba, Luz María: "La Reparación en el Marco del Derecho Penal Medioambiental”. 
miembros de la Comisión Nacional del Medio Ambiente. Posteriormente, al presentarse el texto a la Comisión Foro Penal, se introdujeron modificaciones al articulado primitivo para adecuarlo a la sistemática general del anteproyecto e incorporar las observaciones de los miembros de la Comisión.

Siguiendo el esquema desarrollado en la investigación que dio origen a esta propuesta, sus fundamentos se exponen en siete partes, correspondiendo las seis primeras al texto del Informe Final del mencionado Proyecto Fondecyt 1010206-2001: la primera aborda la cuestión de la necesidad de un derecho penal protector del medio ambiente, ante los riesgos a que se encuentra sometido en las sociedades contemporáneas; la segunda, la necesidad de su regulación desde el punto de vista del derecho internacional y las obligaciones contraídas en la materia; la tercera, una descripción sucinta de los modelos de regulación de la protección penal del medio ambiente en el derecho comparado; la cuarta, una explicación de las normas de derecho penal ambiental vigentes en Chile; la quinta, el porqué de la insuficiencia legislativa penal para la protección del medio ambiente, a la luz de las obligaciones internacionales contraídas en la materia, el estado del derecho comparado y la necesidad de evitar la burla del Sistema de Evaluación de Impacto Ambiental; la sexta, una reseña y crítica científica de los proyectos de ley en materia penal ambiental presentados al Congreso Nacional, y la séptima, los fundamentos del proyecto de articulado presentado a la Comisión Foro Penal y el texto de la propuesta del proyecto de ley elaborado, producto final de nuestras investigaciones.

\section{La conciencia de los peligros ambientales y el sistema chileno de protección del medio ambiente}

Como lo demuestra la realización de este seminario en el Centro de Estudios Públicos, ya es un lugar común afirmar que asistimos en la actualidad al escenario de una progresiva preocupación a nivel nacional e internacional por los peligros que, para la vida y la salud de las actuales y futuras generaciones, entrañan los fenómenos de degradación ambiental propios del estado actual del desarrollo económico y social de nuestra comunidad. Es, naturalmente, esta preocupación la que motiva la pregunta acerca de la necesidad de una regulación penal de los graves atentados contra el medio ambiente y, consecuentemente, de la forma en que dicha regulación debiera plantearse.

Esta preocupación de nuestra comunidad se refleja en la cobertura informativa que se ha dado a diversos fenómenos propios de nuestro tiempo, que van más allá de las periódicas saturaciones de contaminantes en el 
aire de nuestras ciudades ${ }^{4}$, tales como episodios de grave contaminación de las aguas de los ríos ${ }^{5}$ y mares ${ }^{6}$, etc. Últimamente, además, hemos visto la preocupación de la prensa por otro problema propio de las sociedades contemporáneas: el tratamiento de la producción de residuos de toda naturaleza, que podrían llegar a contener ciertas sustancias especialmente nocivas, y cuando no es ése el caso, su sola acumulación sin control ni tratamiento adecuado puede revestir un alto grado de gravedad y peligrosidad para el medio ambiente y la salud de las personas ${ }^{7}$. A estos fenómenos han de sumarse los peligros para la mantención de las propiedades del aire, el agua y los suelos que se originan en la necesaria producción y transporte de elementos nucleares, químicos, biológicos y otras sustancias peligrosas, actividades que, fuera de control, pueden incluso afectar directa e indirectamente la vida y la salud de las personas y de la flora y fauna nacionales ${ }^{8}$.

${ }^{4}$ Ver al respecto las múltiples notas de prensa surgidas en relación con la contaminación ambiental en el Gran Santiago, particularmente las referidas a las alertas ambientales ocurridas el año 2002 (por todos, El Mercurio, de 4 de mayo de 2002, Cuerpo C). Pero también existen otros riesgos de contaminación del aire no siempre igual de destacados, pero a veces de mayor gravedad para la salud de quienes los padecen, como la contaminación por plomo y cobre sufrida por un sector de la ciudad de Antofagasta (El Mercurio, 9 de noviembre de 2002, Cuerpo C). Entre la bibliografía científica, pueden verse los textos de Hajek, Ernst, Guillermo Espinoza y Patricio Gross: Percepción de los Problemas Ambientales en las Regiones de Chile, 1994; varios autores: Gestión Ambiental del Gobierno de Chile, 1997; y Geisse G., Guillermo: 10 Años de Debate Ambiental, 1993.

${ }^{5}$ Ver al respecto, la noticia referida a las emergencias ambientales por derrames mineros en el tranque Talabre (Calama) y en el río Elqui (El Mercurio, 9 de noviembre de 2002, Cuerpo C).

${ }^{6}$ El último ejemplo de lo cual es el grave suceso del hundimiento del buque petrolero Prestige, y el posterior derrame de su cargamento en las costas gallegas (Emol, 30 de noviembre de 2002).

${ }^{7}$ El ejemplo más paradigmático es el problema suscitado por el control de los vertederos y el depósito de residuos sólidos, reflejado en el editorial de La Tercera, de 14 de febrero de 2002. Esta preocupación también se ha reflejado a nivel parlamentario en las mociones contenidas en el Boletín 150-11, donde se intentó legislar para prohibir el ingreso al territorio nacional de desechos provenientes de terceros países; en el Boletín 2401-12, sobre un proyecto de ley que establece penalidades a los vertederos clandestinos; y en el Boletín 2721-12, que contenía un proyecto de ley que prohibía el traslado y posterior depósito de basuras y desperdicios generados en una región, en el territorio de otra.

${ }^{8}$ Juan Claudio Godoy, alcalde de San Miguel y presidente de Emeres, informó a la Comisión de Recursos Naturales, Bienes Nacionales y Medio Ambiente de la Cámara de Diputados (Sesión 35a de la 342 ${ }^{\mathrm{a}}$ Legislatura, 5.09.2000), que en ese año a un vehículo que transportaba cloro al 8\%, sin autorización ni medidas de prevención adecuadas, se le cayó una bolsa en la Autopista del Sol, lo cual dio como resultado que ocho funcionarios municipales y cuatro bomberos fueran hospitalizados. Ver, además, el estudio "Riesgo y Costo Social del Transporte de Sustancias Peligrosas en la Minería”, por Andrés Wrann, Marcelo Andía y Gustavo Lagos, del Centro de Investigación Minero Metalúrgico y Pontificia Universidad Católica de Chile, Informe de Avance, mayo 2000, en http://www.cipma.cl/ hyperforum/chile1.doc. 
Para enfrentar estos fenómenos, el derecho del medio ambiente en Chile ha experimentado numerosos y significativos cambios en los últimos diez años, los cuales, como es sabido, han estado orientados a establecer, por una parte, una Institucionalidad Ambiental, conformada por la Comisión Nacional del Medio Ambiente y sus respectivas comisiones regionales; y por otra, un conjunto de instrumentos jurídicos, entre los que destacan el Sistema de Evaluación del Impacto Ambiental de las actividades y proyectos que inciden en el medio ambiente, y las Normas de Calidad y de Emisión dictadas en su conformidad, instrumentos inspirados en el propósito de lograr un desarrollo sustentable que permita, en el corto, mediano y largo plazo, el cumplimiento de estándares o normas de calidad ambiental que permitan el cabal disfrute de todos los chilenos del derecho consagrado en el artículo $19 \mathrm{~N}^{\circ} 8$ de nuestra Carta Fundamental.

Así, mientras el Sistema de Evaluación del Impacto Ambiental pretende lograr una adecuada prevención y control de las actividades que podrían llegar a originar daños ambientales, la promulgación progresiva de Normas de Calidad Ambiental fija las metas ambientales generales para todo el territorio o parte de él y, especialmente, los objetivos y acciones a realizar para mantener las propiedades del ambiente sano y libre de contaminación; en tanto que las Normas de Emisión permiten fijar las cantidades máximas de emisión de contaminantes a cada fuente individual, estableciendo mecanismos de adaptación progresiva a dichos límites de las actividades sujetas a control.

Sin embargo, no existen en la Ley N 19.300 ni en los restantes instrumentos ambientales mecanismos de carácter penal establecidos directamente para sancionar a quienes causen un grave daño ambiental o burlen derechamente el Sistema de Evaluación de Impacto Ambiental, lo cual hace ilusorias sus finalidades.

En efecto, el Título III de la Ley N 19.300 establece, por una parte, una acción de carácter civil derivada solamente de daños ambientales y que se rige por los criterios tradicionales de responsabilidad extracontractual (artículo 51, inc. final), particularmente en lo referido a la prueba del dolo o la culpa civil (artículo 51, inc. primero) y de la relación de causalidad para efectos de obtener una indemnización (artículo 52). Estas limitaciones son mitigadas por la existencia de una acción de carácter meramente reparatorio del ambiente (artículo 53), respecto de la cual se abre un abanico de personas legitimadas para actuar (artículo 54) y se establece un procedimiento sumario algo más expedito que el juicio ordinario civil (artículos 60 y siguientes).

Por otra parte, las sanciones que se establecen en el artículo 57 de la Ley 19.300, respecto de los responsables de fuentes emisoras que infrinjan 
regulaciones relativas a los planes de prevención o descontaminación, o a las regulaciones especiales para situaciones de emergencia ambiental, si bien permiten castigar por una vía que parece indicada (salvo en cuanto supone la realización de un juicio civil ante la judicatura ordinaria) ciertas infracciones de carácter menor a normas medioambientales, claramente son insuficientes preventivamente respecto de hechos de grave contaminación ambiental o peligro de ella, puesto que las normas de emisión y de calidad ambiental están referidas a finalidades de gestión que toman en cuenta factores acumulativos, territoriales, temporales, y hasta estacionales, los que hacen difícil identificar hechos que por sí mismos puedan considerarse como de grave daño ambiental.

Lamentablemente, tampoco el sistema fiscalizador de carácter administrativo dispuesto en el artículo 64 de la Ley $\mathrm{N}^{\circ} 19.300$ parece suficiente para los propósitos antes enunciados, básicamente por reducir su aplicabilidad al control del adecuado cumplimento de las condiciones en que se autorizaron los proyectos o actividades sometidos al Sistema de Evaluación de Impacto Ambiental, dejando a las Comisiones Regionales y Nacional del Medio Ambiente impedidas de aplicar la fuerte multa que allí se dispone (hasta 500 UTM) a quienes sencillamente burlen el Sistema de Evaluación de Impacto Ambiental ${ }^{9}$ o causen graves daños ambientales no vinculados a proyectos o actividades sujetos a dicho sistema, etc. Asimismo, se crea un sistema burocrático, con un procedimiento que no está claramente descrito en la ley, y que opera, en la actualidad, a través de "Comités Operativos de Fiscalización”, cuya constitucionalidad y legalidad son dudosas ${ }^{10}$.

Incluso la referencia que en dicho artículo 64 de la Ley $\mathrm{N}^{\circ} 19.300$ se hace al ejercicio por parte de las Comisiones Regionales o Nacional de las "acciones... penales que sean procedentes", parece de muy difícil aplicación práctica, pues, como veremos a continuación, el resultado de nuestras investigaciones demuestra que las normas penales relativas al medio am-

${ }^{9}$ Como la propia Contraloría General de la República ha reconocido en su Dictamen $\mathrm{N}^{\circ}$ 8.988, de 14 de marzo de 2000, no existen sanciones en la Ley $\mathrm{N}^{\circ} 19.300$ para quienes infringen la obligación en ella establecida de someter los proyectos o actividades que se señalan en su artículo 10 al Sistema de Evaluación de Impacto Ambiental (Cfr. Bascuñán Muñoz, Juan Francisco: Jurisprudencia de la Contraloría General de la República Relativa al Sistema de Evaluación de Impacto Ambiental: 1997-2000, 2001.

${ }^{10}$ En efecto, cuando se discutió el artículo 77 de la Ley 19.300, Sobre Bases Generales del Medio Ambiente, se acordó en el Senado otorgar al director ejecutivo de la Conama la faculta de crear comités operativos, como "comités consultivos para el estudio, consulta, análisis y coordinación en materias relativas al medio ambiente”, posibilitando la incorporación de personas ajenas a la Conama, pero sin hacer en ningún momento referencia a una función fiscalizadora y sancionatoria, como la que ha derivado en la práctica (Cfr. Toledo Tapia, Fernando: Ley 19.300, sobre Bases Generales del Medio Ambiente, Historia Fidedigna y Concordancias Internas, 1996, p. 249). 
biente vigentes en Chile parecen insuficientes — si se contraponen a la luz del estado actual del derecho internacional (y de las obligaciones contraídas en ese ámbito) y del derecho comparado- para sancionar adecuadamente a quienes causan sucesos de grave contaminación o daño ambiental, ponen en grave peligro al medio ambiente $y$, consiguientemente, a nuestra comunidad, o burlan el Sistema de Evaluación de Impacto Ambiental.

\section{Las exigencias impuestas por el derecho internacional en materia penal ambiental}

En cuanto a la preocupación de la comunidad internacional —y del Estado de Chile como parte de la misma-, a partir de la década de 1950, con la celebración del Convenio de Londres de 1954, para la Prevención de la Contaminación del Mar por Hidrocarburos y, con mayor fuerza, con posterioridad a la Declaración adoptada en la Conferencia de las Naciones Unidas sobre el Medio Humano celebrada en Estocolmo del día 5 al 16 de junio de 1972, aquélla se ha visto reflejada en un impresionante corpus de declaraciones, resoluciones, tratados multi y bilaterales, etc. ${ }^{11}$, en el cual aparece como una idea-fuerza constante la necesidad de sancionar penalmente, y con independencia del régimen administrativo, las graves infracciones a la regulación ambiental de cada país, idea que se recoge en el Principio 11 de

${ }^{11}$ No es claro el número total de tratados, convenciones, declaraciones, etc., que directa o indirectamente tienen relación con el medio ambiente. Flavio Fuentes Olivares, en su Manual de Derecho Ambiental, 1999, pp. 119 y ss., señala que existirían más de 4.000 instrumentos jurídicos en la materia, de los cuales, "de carácter estrictamente internacional, con pretensión de universalidad y globalidad, hay alrededor de 152"; en tanto que González, Sánchez y Sáenz: Curso de Derecho Internacional Público, 1998, p. 792, hablan de "varios centenares de textos". En recopilaciones elaboradas por la doctrina iuspublicista, podemos señalar que el volumen de Wirnie, Patricia W. y Alan Boyle, Basic Documents on International Law and the Environment, 1995, enumera a esa fecha alrededor 40 instrumentos que pueden considerarse como punto de partida para el estudio del derecho internacional ambiental. Por su parte, respecto a los instrumentos suscritos por la República de Chile, el profesor Hugo Llanos Mansilla, en su trabajo, también de 1995, La Protección Jurídica del Medio Ambiente en Chile: Convenios Internacionales, transcribe más de 70 tratados, convenciones y declaraciones relativos a la materia. Para efectos de su estudio particular, nuestra Comisión Nacional del Medio Ambiente ha realizado una selección de los tratados internacionales relativos al ambiente, considerando como más relevantes para Chile un grupo de aproximadamente 20 tratados, incluyendo sus respectivos protocolos, cuyos principales contenidos, con referencia a su grado de cumplimiento a nivel nacional, se recopilan en la obra de Montenegro, Sergio, Domique Hervé y Valentina Durán: Los Tratados Ambientales: Principios y Aplicación en Chile, 2001. Por su parte, el PNUMA, en su texto Derecho Internacional Ambiental Regional, recopila 31 tratados y convenciones aplicables en América Latina. 
la Declaración de Río sobre el Medio Ambiente y el Desarrollo, Conferencia de las Naciones Unidas sobre el Medio Ambiente y el Desarrollo, Río de Janeiro, 3 al 14 de junio de 1992, donde se insiste en la necesidad de que "los Estados deberán promulgar leyes eficaces sobre el medio ambiente", que reflejen "el contexto ambiental y de desarrollo al que se aplican”.

Esta necesidad, en los términos de la Comisión de las Naciones Unidas para la Prevención del Delito y la Justicia Criminal (fundida actualmente con la Oficina de las Naciones para el Control de las Drogas y la Prevención del Delito), debe traducirse en una activa participación de la "justicia criminal en la protección del medio ambiente” y en la adopción por parte de los Estados de disposiciones penales que castiguen: a) infracciones que tuviesen o pudiesen tener efectos transfronterizos que afectasen a la comunidad internacional toda, como las relativas a las emanaciones de gases invernadero; b) infracciones que tuviesen efectos en un país distinto del lugar donde se cometen, y c) infracciones que pudiesen ser consideradas graves “delitos contra el medio ambiente” en cualquier país, entre los que debieran incluirse los relativos al patrimonio cultural, los relativos al manejo de desechos tóxicos y a la flora y fauna; y el cambio de la tradición romanista contraria a la responsabilidad penal de las personas jurídicas, considerada como "un instrumento ineficaz para combatir los delitos graves contra el medio ambiente porque la gran mayoría de los delitos de degradación ambiental era atribuible a entidades privadas y públicas”12.

Ya en particular, la necesidad de adoptar un régimen jurídicamente más coercitivo para prevenir daños ambientales aparece claramente en una serie de tratados y convenciones suscritos por Chile y que se encuentran vigentes, que abordan la protección del ambiente desde distintos puntos de vista, imponiendo obligaciones de diversa índole en orden a la:

\section{a) Protección penal medio ambiente antártico}

El artículo 13.1 del Protocolo del Tratado Antártico sobre Protección del Medio Ambiente, Madrid, 4 de octubre de 1991, señala que “cada Parte tomará medidas adecuadas en el ámbito de su competencia para asegurar el cumplimiento de este Protocolo, incluyendo la adopción de leyes y reglamentos, actos administrativos y medidas coercitivas”.

${ }^{12}$ Informe de la Reunión del Grupo Especial de Expertos sobre las Formas Más Eficaces de Cooperación Internacional contra la Delincuencia Transnacional, Viena, diciembre de 1993 (E/CN.4/1994/4/Add.2,10) y del Noveno Congreso de las Naciones Unidas Sobre Prevención del Delito y Tratamiento del Delincuente, El Cairo, 29 de abril a 8 de mayo de 1995 (A/CONF.169/16, 352-361). 
b) Protección penal del medio ambiente frente a los peligros de las armas de destrucción masiva

El artículo 7 de la Convención sobre la Protección Física de los Materiales Nucleares, Viena/Nueva York, de 3 de marzo de 1980, establece que "la comisión intencionada" de los actos que se detallan, relacionados con el tráfico ilícito de materiales nucleares (plutonio y uranio en su estado no mineral) “(1) será considerada como delito punible por cada Estado Parte en virtud de su legislación nacional” y que “(2) cada Estado Parte deberá considerar punibles los delitos descritos [...] mediante la imposición de penas apropiadas que tengan en cuenta la gravedad de su naturaleza”. También relacionado con los materiales nucleares, el artículo I del Tratado que Prohíbe las Pruebas de Armas Nucleares en la Atmósfera, en el Espacio Exterior y el Mar, Moscú, 5 de agosto de 1963, obliga a los Estados a “prohibir” “el desarrollo, la producción, el almacenamiento, la adquisición o la retención de los agentes, toxinas, armas [biológicas], equipos y vectores”, por una parte; y realizar una “explosión de prueba de armas nucleares” u “otra explosión nuclear”, por otra. Finalmente, similares obligaciones establece el artículo IV de la Convención sobre la Prohibición del Desarrollo, la Producción y el Almacenamiento de Armas Bacteriológicas (Biológicas) y Toxínicas y sobre su Destrucción, Londres/Moscú/Washington, 1972.

c) Protección penal del medio ambiente, y particularmente de los suelos, frente al tráfico ilícito de desechos peligrosos

La Convención de Basilea sobre el Control de los Movimientos Transfronterizos de Desechos Peligrosos y su Eliminación, de 1989, establece en su artículo 4 que “(3) las Partes considerarán que el tráfico ilícito de desechos peligrosos y otros desechos es delictivo”, agregando, en consecuencia, como obligación específica, en su artículo 9, que “(5) cada Parte promulgará las disposiciones legislativas nacionales adecuadas para prevenir y castigar el tráfico ilícito”.

\section{d) Protección penal de las aguas y particularmente de las marinas}

El artículo 4 del Convenio Internacional para Prevenir la Contaminación por los Buques (MARPOL 1973/1978), y particularmente la derivada de los derrames incontrolados de hidrocarburos, señala que "toda transgresión de las disposiciones del presente Convenio... estará prohibida y será sancionada por la legislación de la Administración del buque interesado”, y el 
tenor del artículo 192 de la Convención de las Naciones Unidas sobre el Derecho del Mar de 1982 hace suponer casi sin lugar a dudas la necesidad de adoptar disposiciones legales en el orden interno de carácter penal encaminadas a "proteger y preservar el medio ambiente marino", y a prevenir, reducir y controlar la contaminación del medio marítimo en sus diversas manifestaciones, obligaciones extensibles a las prohibiciones que dispone el artículo VII del Convenio sobre Prevención de la Contaminación el Mar por Vertimientos de Desechos y otras Materias de 1972.

Además, facultando a los Estados para imponer sanciones de carácter penal que protejan las aguas marinas, encontramos el artículo III del Protocolo para la Protección del Pacífico Sudeste Contra la Contaminación Proveniente de Fuentes Terrestres, Quito, 22 de julio de 1983; y el artículo II del Protocolo para la Protección del Pacífico Sudeste Contra la Contaminación Radioactiva, Paipa (Colombia), 1981.

\section{e) Protección penal de la biodiversidad y, en particular, de la fauna silvestre}

La más antigua disposición al respecto es la Convención Internacional para la Regulación de la Caza de Ballenas y su Anexo, Washington, de 2 de diciembre de 1946, cuyo artículo IX dispone que “(1) cada Gobierno Contratante tomará las medidas apropiadas para asegurar la aplicación de las disposiciones de la presente Convención y la sanción para las infracciones a tales disposiciones en las operaciones efectuadas por personas o por naves bajo su jurisdicción”, agregando: “(3) los juicios por infracciones o contravenciones a esta Convención serán entablados por el Estado que tenga jurisdicción sobre tales delitos”.

Actualmente, la Conferencia de las Partes de la Convención Sobre el Comercio Internacional de Especies Amenazadas de Fauna y Flora Silvestres (CITES), Washington, 3 de marzo de 1973, entiende que dicho tratado obliga a las partes a establecer estrictas medidas de control sobre el tráfico ilícito de ejemplares de especies en peligro y adoptar, en caso de violación de esas medidas de control, "las medidas apropiadas, en conformidad al Artículo VIII, párrafo 1, de la Convención, en orden a penalizar tales violaciones"13.

Además, el artículo 8 del Convenio sobre la Diversidad Biológica, adoptado en la misma Conferencia Internacional de Río de Janeiro, el 5 de junio de 1992, “obliga” a “cada parte Contratante, en la medida de lo posible

${ }^{13}$ Resolutions of the Conference of the Parties to CITES in Effect after the 11th Meeting, CITES Secretariat, Châtelaine-Genève 2000, Res. 11.3, p. 119. 
y según proceda”, a establecer "un sistema de áreas protegidas o áreas donde haya que tomar medidas especiales para conservar la diversidad biológica” y "la legislación necesaria y/u otras disposiciones de reglamentación para la protección de especies y poblaciones amenazadas”. Junto a este tratado existen también otros que se refieren a particulares elementos de la fauna y flora silvestres dignos de protección, en que se faculta a los Estados a adoptar medidas coercitivas, incluidas las penales, por supuesto. Entre ellos tenemos: el artículo 2 (2) de la Convención Sobre Conservación de Focas Antárticas, y su Apéndice, Londres, 1 de junio de 1972; el artículo V de la Convención para la Protección de la Flora, la Fauna y las Bellezas Escénicas Naturales de América, Washington, 12 de octubre de 1940; los artículos $2^{\circ}$ y $4^{\circ}$ del Convenio para la Conservación y Manejo de la Vicuña, Lima, diciembre de 1979; el artículo tercero del Convenio sobre Resguardo de Bosques Fronterizos contra Incendios, suscrito entre el Gobierno de Chile y el de Argentina, Santiago de Chile, 22 de diciembre1961; y los artículos 2 y 3 de la Convención sobre Prohibición de Pesca con Redes de Deriva de Gran Escala en el Pacífico Sur, 1989, Wellington, y su Protocolo de 1990.

\section{Los modelos de regulación de la protección penal del medio ambiente en el derecho comparado}

Siguiendo los dictados de los tratados y convenciones internacionales, y afrontando derechamente la preocupación de las sociedades actuales por la degradación del medio ambiente, en buena parte de las naciones de nuestra órbita cultural podemos encontrar recientes modificaciones legales que abordan directamente la protección penal del medio ambiente o de la institucionalidad ambiental, asumiendo de este modo la insuficiencia de las vías civiles y administrativas para afrontar los problemas derivados de la degradación del medio ambiente en el estadio de desarrollo social y cultural en que nos encontramos. Entre estas soluciones normativas al problema de la regulación de la protección penal del medio ambiente podemos destacar las siguientes:

\section{III.1. Los delitos contra el medio ambiente en el derecho de tradición continental}

Entre las legislaciones de tradición continental que han establecido nuevas figuras penales que castigan de manera más o menos independiente hechos que afecten o pongan en peligro el medio ambiente, podemos en- 
contrar dos modelos diferentes de tratamiento del llamado delito ambiental: el de regulación general y el de regulación especial. La diferencia entre los modelos radica, básicamente, en la técnica legal empleada: en el primero los delitos de contaminación aparecen en el Código Penal (así, en Europa, España y Alemania), mientras que en el modelo de regulación especial el legislador ha optado por incorporar tales delitos en una ley especial relativa al medio ambiente, que regula la protección del medio ambiente como objeto especial, tanto en los aspectos penal, procesal y administrativo (así, en Latinoamérica, Brasil).

Entrando en algún detalle, podemos constatar que de entre las legislaciones que siguen el modelo de regulación general, el Código Penal español de 1995 establece en el Capítulo III del Título XVI de su Libro segundo, artículos 325 a 331, los llamados "delitos contra los recursos naturales y el medio ambiente". En ese título, denominado genéricamente "delitos relativos a la ordenación del territorio y la protección del patrimonio histórico y del medio ambiente", se contemplan también los "delitos contra la ordenación del territorio" (Cap. I), los que recaen "sobre el patrimonio histórico" (Cap. II), y los "relativos a la protección de la flora y fauna". Entre el variado catálogo de figuras penales que se contemplan en las disposiciones aludidas parece haber acuerdo en la doctrina de que el delito referido a la afectación propia del medio ambiente como tal sería el contemplado en el artículo 325, conocido como "delito ecológico" o "de contaminación", que recoge con algunas alteraciones el antiguo artículo 347 bis del Código Penal de 1944 (introducido por la Ley Orgánica 8/1983 de 25 de junio) y castiga con penas privativas de libertad, multa e inhabilitación al que, "contraviniendo las Leyes u otras disposiciones de carácter general protectoras del medio ambiente, provoque o realice directa o indirectamente emisiones, vertidos, radiaciones, extracciones o excavaciones, aterramientos, ruidos, vibraciones, inyecciones o depósitos, en la atmósfera, el suelo, el subsuelo, o las aguas terrestres, marítimas o subterráneas, con incidencia, incluso, en espacios transfronterizos, así como las captaciones de aguas que puedan perjudicar gravemente el equilibrio de los sistemas naturales"14. En el mismo artículo 325 se contempla una primera agravación, consistente en provocar un "riesgo de grave perjuicio... para la salud de las personas". El mismo efecto agravante se establece en el artículo 326 cuando en la comisión del delito concurra alguna de las circunstancias siguientes: “a) Que la industria o actividad funcione clandestinamente, sin haber obtenido la preceptiva autorización o aprobación administrativa de sus instalaciones; b) Que se

${ }^{14} \mathrm{Cfr}$., los textos citados en las notas 2 y 3 , supra. 
hayan desobedecido las órdenes expresas de la autoridad administrativa de corrección o suspensión de las actividades tipificadas en el artículo anterior; c) Que se haya falseado u ocultado información sobre los aspectos ambientales de la misma; d) Que se haya obstaculizado la actividad inspectora de la Administración; e) Que se haya producido un riesgo de deterioro irreversible o catastrófico; y f) Que se produzca una extracción ilegal de aguas en período de restricciones”. En figuras aparte, el artículo 328 castiga con la pena de multa y arresto de fin de semana a quienes establecieren depósitos o vertederos de desechos o residuos sólidos o líquidos que sean tóxicos o peligrosos y puedan perjudicar gravemente el equilibrio de los sistemas naturales o la salud de las personas; y el artículo 330 impone la pena de prisión de hasta cuatro años y multa a "quien, en un espacio natural protegido, dañare gravemente alguno de los elementos que hayan servido para calificarlo".

Por su parte, la legislación alemana reunió (18 $8^{\mathrm{a}}$ Ley de Reforma del Derecho Penal de 1980 y Segunda Ley para el Combate de la Criminalidad Ambiental de 1994 — $31^{\text {a }}$ Ley de Reforma del Derecho Penal—) en el actual Capítulo 29 de su Código Penal, §§324ss, bajo el epígrafe "Delitos contra el medio ambiente", la mayor parte de los hechos de contaminación punibles que recaen sobre los "medios del ambiente", estableciendo tipos penales diferentes para cada uno de ellos (agua, aire, suelo), junto con previsiones específicas para la protección de la flora y fauna, figuras penales antes dispersas en leyes especiales, siguiendo —al decir de Tiedemann — "la nueva política criminal alemana de ubicar todos los delitos importantes en el Código Penal común”, pues "son los delitos incluidos en el Código Penal los que interesan no sólo (y en cuanto tales) al público sino especialmente a los juristas, comenzando por los estudiantes y terminando por los jueces y por la doctrina penal", como una forma de hacer patente "la idea de que estamos ante una verdadera delincuencia [que] merece ser tomada seriamente en cuenta" ${ }^{\prime 15}$. Actualmente, el derecho penal ambiental alemán contempla las siguientes figuras penales: contaminación o alteración no autorizada del agua o de sus propiedades físicas (§324); aterramiento o depósito de materiales en el suelo, en importantes cantidades o poniendo en peligro serio la salud de las personas o la vida animal, vegetal y la pureza de las aguas, en contravención al ordenamiento administrativo (§324a); emisión e inmisión en el aire de sustancias no autorizadas, que puedan causar serios daños a la salud de las personas, la vida animal o vegetal, o la pureza de las aguas (§325); producción no autorizada de ruidos que puedan causar daños

15 Tiedemann, Klaus: Lecciones de Derecho Penal Económico (Comunitario, Español, Alemán), 1993, pp. 175 y ss. 
a la salud de las personas o serios daños a los animales y propiedades ajenas (§325a); verter, tratar, trasladar, o evacuar residuos químicos peligrosos o radiactivos no autorizados o fuera del margen de una autorización (§326); el establecimiento y administración no autorizados de instalaciones de energía nuclear, o de otras empresas productivas o extractivas que deban contar con autorización especial (§327); la realización no autorizada de operaciones o tratamientos con combustibles nucleares y otros elementos radiactivos (§328); la contaminación industrial no autorizada del aire durante períodos de emergencia ambiental ${ }^{16}$, la de aguas o fuentes de agua especialmente protegidas, así como la destrucción o alteración de parques naturales y áreas protegidas (§329). Estas figuras pueden agravarse, en un primer orden, cuando la contaminación producida pueda llegar a permanecer "largo tiempo", con ella se ponga en peligro el suministro de agua a la población, se amenace la existencia de una especie animal o vegetal, o se haya producido por puro "afán de lucro"; y en segundo lugar, cuando se haya causado la muerte de una persona o se haya puesto en grave peligro la vida o salud de una persona o se haya puesto en peligro la salud de un número indeterminado de personas (§330). Además, el §330a contempla una figura especial y agravada de peligro concreto para la salud y vida de las personas, consistente en la diseminación o liberación de venenos o sustancias que pueden transformarse en venenos que causen el peligro de muerte o de grave daño a la salud de otro o de daño en la salud de un número indeterminado de personas, que, según la doctrina mayoritaria, concurre idealmente con el resto de los delitos que protegen el medio ambiente ${ }^{17}$.

En Brasil, en cambio, donde se sigue el modelo de regulación especial, es una ley separada del Código Punitivo - la Ley N 9.605, de 12 de febrero de 1998, que establece sanciones penales y administrativas derivadas de conductas o actividades lesivas contra el medio ambiente-, donde se encuentran las sanciones penales en esta materia, las cuales, respondiendo a la exigencia constitucional contemplada en el artículo 225 §3 de la Constitución Federal de 1988, castigan penalmente a quienes realicen actividades o conductas lesivas para el medio ambiente, sean personas naturales o jurídicas ${ }^{18}$. Desde el punto de vista formal, dicha ley consta de 8 capítulos y 82 artículos, que desarrollan un amplio abanico de materias, no sólo pe-

${ }^{16}$ No aplicable a los conductores de automóviles, quienes se rigen sólo por las disposiciones de policía del tráfico rodado (Fischer: Strafgesetzbuch und Nebengesetze, 2008, p. 1798).

${ }^{17}$ Cramer, Peter: "Comentarios a los Artículos 324ss del Código Penal”, 1997, p. 2247.

${ }^{18}$ Ver Leme Machado, Paulo Affonso: Direito Ambiental Brasileiro, 1992, pp. 460 y ss. 
nales (comprendidas en su Capítulo V), sino también infracciones administrativas, aplicación de la pena, ejercicio de la acción y el proceso penal, cooperación internacional para la preservación del medio ambiente, etc. En particular, el mencionado Capítulo V se divide en cinco secciones que tratan las siguientes materias: la Sección I "De los Delitos contra la Fauna”; la Sección II "De los Delitos contra la Flora”; la Sección III “De la Contaminación y otros Delitos Ambientales”; la Sección IV “De los Delitos contra el Ordenamiento Urbano y el Patrimonio Cultural”, y la Sección V "De los Delitos contra la Administración Ambiental”19. En cuanto a los delitos de contaminación propiamente tales, particular interés merece el artículo 54 de la ley, que contempla propiamente el delito de contaminación, castigando con pena de reclusión de uno a cuatro años y multa el "causar polución de cualquier naturaleza en niveles tales que resulten o puedan resultar de ella daños a la salud humana, o que provoquen una mortandad de animales o una destrucción significativa de la flora”; sancionándose además, con una pena inferior, su comisión culposa (artículo $54 \S 1^{\circ}$ ). Las penas se agravan cuando la contaminación afecta directamente un área habitada, el agua potable, las playas o se comete por vertimiento de basuras o hidrocarburos (artículo $54 \S 2^{\circ}$ ), o cuando se omite adoptar las medidas preventivas de un daño ambiental grave o irreversible, ordenadas por la autoridad competente (artículo 54, §3º). En esta sección se contemplan además dos delitos que castigan hechos potencialmente contaminadores, pero sin relacionar su comisión con la contaminación propiamente tal. Así, el artículo 56 sanciona penalmente el "producir, procesar, embalar, importar, exportar, comercializar, guardar, transportar, almacenar, tener en depósito o usar productos o substancias tóxicas, peligrosas o nocivas para la salud humana o el medio ambiente, sin cumplir las exigencias legales o reglamentarias”. En este delito también se castiga el abandono de tales sustancias o su utilización en contra de las normas de seguridad (artículo $56 \S 1^{\circ}$ ), y su comisión culposa (artículo 56, $\S 3^{\circ}$ ), agravándose la pena en caso de que la sustancia sea “nuclear o radioactiva” (artículo 56, §2º). Por su parte, el artículo 60 castiga el "construir, reformar, ampliar, instalar o hacer funcionar, en cualquier parte del territorio nacional, establecimientos, obras o servicios potencialmente contaminadores, sin licencia o autorización de los órganos ambientales competentes, o en contravención a las normas legales y reglamentarias aplicables”. Finalmente, se dispone que las penas de estos delitos se agravan todavía más en casos de contaminación dolosa, cuando "resulta un daño

${ }^{19}$ El único delito de esta sección que no tiene relación directa con el tratamiento de la participación de los funcionarios públicos en actos de contaminación es el del artículo 69, una especie de desacato administrativo, que castiga el "obstar ou dificultar a ação fiscalizadora do Poder Público no trato de questões ambientais ...”. 
irreversible a la flora o al medio ambiente en general” (art. 58, I); "resulta una lesión corporal grave en otra persona” (artículo 58, II), y cuando "resulta la muerte de otro" (artículo 58, III).

\section{III.2. Los delitos contra el medio ambiente en el common law. El sistema norteamericano}

Como principal característica del derecho penal ambiental en los Estados Unidos tenemos su fragmentación en diversas leyes, protectoras a su vez de los distintos componentes del medio ambiente, a saber: la Clean Air Act (CAA), sobre contaminación del aire y la atmósfera ${ }^{20}$; la Clean Water Act (FWPCA), sobre contaminación de las aguas ${ }^{21}$; la Resource Conservation and Recovery Act (RCRA), para tratar el problema del manejo de los desechos peligrosos, "desde la cuna hasta la tumba"22; la Comprehensive Environmental Response, Conservation and Liability Act (CERCLA), que estableció mecanismos para la limpieza de los sitios contaminados con desechos peligrosos ${ }^{23}$, y finalmente la Federal Insecticide, Fungicide and Rodenticide Act (FIFRA) y la Toxic Substances Control Act (TSCA), que introducen delitos ambientales en el ámbito de las sustancias químicas ${ }^{24}$.

El desarrollo normativo del derecho penal del medio ambiente en los Estados Unidos no se agotó con la promulgación de estos estatutos, sino que más bien ha seguido una sostenida expansión, mediante modificaciones sucesivas y sustanciales a dichas leyes, con la intención explícita de fortalecer el programa de protección penal del medio ambiente. Es así como, por ejemplo, ciertas faltas se elevaron a la categoría de crímenes, se eliminaron ciertos elementos subjetivos del tipo, se aumentaron las penas y se introdujeron delitos de peligro. Estas innovaciones perseguían fortalecer la capacidad del Estado para hacer efectiva la responsabilidad penal ambiental ${ }^{25}$.

Entre los aspectos más relevantes que distinguen este vasto sistema de protección del medio ambiente, frente a los propios del sistema continental, aparte de la abierta admisión de la responsabilidad penal de las personas jurídicas y de cierta tendencia a objetivizar al extremo las figuras penales, encontramos el hecho de que - aun cuando en última instancia el bien

2033 U.S.C. §7413 documento del The United States Code [U.S.C.], en www. gpoaccess.gov/uscode/browse.html.

2133 U.S.C. §1319, en www.gpoaccess.gov/uscode/browse.html.

2242 U.S.C. §6928, en www.gpoaccess.gov/uscode/browse.html.

2342 U.S.C. §9603, en www.gpoaccess.gov/uscode/browse.html.

247 U.S.C. §136-136y, 15 U.S.C. §2601-2629, respectivamente, en www. gpoaccess.gov/uscode/browse.html.

${ }^{25}$ Ver Schroeder, C.: "Cool Analysis Versus Moral Outrage in the Development of Federal Environmental Criminal Law”, 1993, p. 251. 
jurídico protegido por el sistema penal ambiental es la integridad del medio ambiente, de los elementos que lo componen y de la salud de las personas - su protección se realiza en primera línea mediante el resguardo penal de la integridad del esquema administrativo que establece los mecanismos de protección ambiental. Así, en el entendido de que ciertas declaraciones falsas o la omisión de las mismas usualmente buscan esconder el incumplimiento de la legislación ambiental, y por ende afectan el funcionamiento y los objetivos de conservación del ambiente del sistema administrativo, se castiga penalmente la entrega de información falsa y la mantención de registros falsos por parte de los operadores económicos a quienes se obliga a entregar información sobre una serie de elementos que configuran el impacto ambiental de sus actividades; el omitir la entrega de información a la autoridad, cuando ello es obligatorio por ley; la omisión de entregar notificación inmediata acerca de derrames de petróleo o de liberación de sustancias peligrosas al ambiente, etc. Junto con esta protección del funcionamiento de la administración ambiental, las leyes que regulan la materia también castigan los fenómenos de grave contaminación descontrolados, como la descarga no autorizada de contaminantes al aire o a las aguas, en infracción a los permisos ambientales, diferenciando en estos casos entre simples delitos (felonies), si el agente actuó a sabiendas (knowingly), y faltas (misdemeanors), si el agente actuó de forma negligente (negligently). Además, se contemplan delitos de knowing endangerment, que se acercan a la categoría de lo que nosotros conocemos como delitos de peligro concreto. En ellos se exige que el agente, además de la infracción de la norma o permiso ambiental, haya actuado a sabiendas de que coloca a otra persona en peligro inminente de muerte o de lesiones corporales serias. Estos delitos llevan aparejadas las penas más severas del sistema, hasta 15 años de cárcel y US\$ 250.000 de multa, las cuales son dobladas cuando hay reincidencia. En caso de que el autor del delito sea una organización, las multas penales pueden ascender hasta US\$1.000.000 por cada violación, las que se calculan aparte de las multas administrativas y la reparación del ambiente.

\section{El estado actual de la protección penal del ambiente en Chile. La inexistencia de legislación específica dirigida a la protección penal del medio ambiente}

Como resulta evidente de la presentación de las diversas mociones parlamentarias surgidas en la materia ${ }^{26}$, no existe en Chile una protección penal sistemática y enfocada precisamente a la protección del medio am-

${ }^{26}$ Ver infra, el apartado VI de esta presentación. 
biente en sí, como no existía en la mayor parte de las legislaciones del siglo pasado, básicamente porque al consolidarse la codificación decimonónica no había una preocupación por el medio ambiente propiamente tal, como hemos visto hay hoy en día. En ese sentido, nuestra legislación se encuentra en un estadio de desarrollo del derecho penal ambiental que podríamos denominar de "prescindencia”, en que (como también sucede en otras naciones amigas, como la Argentina ${ }^{27}$ ) la regulación penal de hechos que podrían considerarse como de contaminación o peligro de contaminación o daño ambiental ha de buscarse en disposiciones del Código Penal y de leyes especiales, que no han sido establecidas directa e independientemente con ese propósito, sino con el de proteger otros bienes que, al momento de la codificación o al de dictarse las diversas leyes especiales, se consideraron como dignos de una protección penal, atendiendo a la protección penal de intereses generales (como sucede con algunos delitos contra la salud pública) o específicos en algunos casos (como en muchas leyes especiales). Ahora bien, si ordenamos esas normas desde la perspectiva del medio ambiente y los elementos que lo constituyen, podemos constatar que el sistema chileno de protección penal del medio ambiente está compuesto principalmente por las siguientes normas:

\section{a) Protección penal del aire y la atmósfera}

En la actualidad no existe en nuestro país ningún simple delito o crimen que castigue fenómenos de grave contaminación del aire, pudiendo citarse al respecto sólo las faltas de los números 20 (infracción de las reglas de policía en la elaboración de objetos fétidos o insalubres), 22 (no entregar basuras o desperdicios a la policía de aseo) y 29 del artículo 496 del Código Penal (construcción en contravención de los reglamentos de fuentes de emisión fija — hornos, chimeneas o estufas-), de nula aplicación práctica.

\section{b) Protección penal de las aguas y particularmente de las marinas}

En nuestro Código Penal, el principal delito que protege penalmente la pureza de las aguas es el de su artículo 315, que castiga el envenenamiento o infección de aguas destinadas al consumo público (elaboradas para ser ingeridas por un grupo de personas indeterminadas), reduciendo con ello considerablemente su ámbito de aplicación, más aún si se tiene en cuenta que la contaminación aquí se limita a la proveniente de sustancias que podrían considerarse “venenosas” o “infecciosas”, y al carácter únicamente

${ }^{27}$ Cfr. Libster, Mauricio H.: Delitos Ecológicos, 2000. 
doloso del hecho punible, que excluye los corrientes casos de grave contaminación de mares, ríos o afluentes, causados por evitables y previsibles “accidentes” cuyo origen puede encontrarse en la negligencia, imprevisión o temeridad de quienes controlan las fuentes de emisión. Este delito se agrava seriamente si se produce la muerte o enfermedad grave de una persona (artículo 317 Código Penal), agravación que supone la comprobación de las siempre complicadas relaciones de causalidad entre la contaminación de las aguas y la muerte o enfermedad de una persona. Otros delitos vinculados a la protección de las aguas, relativos más bien a la mantención de sus caudales más que a su contaminación, son los de sacar aguas sin derecho de sus caudales (artículo 459 del Código Penal) y alterar su reparto o permitir su sustracción (artículo 480 Código de Aguas).

Como un propio delito de contaminación de las aguas, particularmente de las marinas, encontramos en la Ley General de Pesca el delito de su artículo 136, por el que se castiga al que introdujere o "mandare a introducir” en el mar, ríos, lagos o cualquier otro cuerpo de agua, agentes contaminantes químicos, biológicos o físicos que causen daño, sin que previamente hayan sido neutralizados para evitar tales daños. Con lo importante que resulta como modelo de regulación la decisión de contemplar expresamente un delito de contaminación y el castigo a quien decide la acción material (“manda a introducir”) aun antes de ejecutarse (lo que transforma a la figura en delito de peligro), la disposición citada deviene en la práctica como de muy difícil aplicación, en primer lugar porque no contempla la figura culposa, que es la de mayor realización fenomenológica, y en segundo término, porque no se define en ella en qué consiste el daño que se pretende evitar, y del cual debe probarse una relación de causalidad con la introducción del agente contaminante, cuyo nivel de neutralización para excluir la tipicidad del hecho tampoco se encuentra fijado por la ley, a pesar de que en ella parece entenderse implícitamente que es posible la introducción de tales agentes a la aguas, siempre que previamente estén neutralizados.

\section{c) Protección penal de los suelos y de los espacios naturales}

Tampoco existe a este respecto un delito que castigue propiamente la grave contaminación de los suelos o la alteración de sus propiedades, y sólo muy indirectamente su degradación podría ser objeto de sanción penal a título de usurpación (artículo 462 del Código Penal), cuando es dolosa y tiene por finalidad alterar o destruir los términos o límites de una propiedad; o a título de infracción al artículo 138 de la Ley General de Urbanismo y 
Construcciones, en que se castiga la venta en verde de loteos que han de ser urbanizados, sin que previamente se cumplan los requisitos que dicha ley establece. Directamente, sólo podría entenderse que el artículo 38 de la Ley de Monumentos Nacionales permitiría la sanción penal de quienes degraden o contaminen seriamente los suelos de los "Santuarios de la Naturaleza”, entendiéndose que dicha contaminación sería una forma de "causar un perjuicio" a tales "Monumentos Naturales ${ }^{28}$.

\section{d) Protección penal de la biodiversidad y, en particular, de la flora y fauna silvestres}

A este respecto, nuestra ley es, sin duda, más pródiga y cumple de mejor manera las prescripciones del derecho internacional, pues no sólo se castiga la propagación sin permiso de la autoridad de enfermedades o plagas animales (artículo 289 del Código Penal), sino también la "propagación indebida" de cualquier organismo, producto, elemento o agente químico, viral, bacteriológico, radiactivo o de cualquier otro orden que por su naturaleza sea susceptible de poner en peligro la salud animal o vegetal, o el abastecimiento de la población. En estas figuras es donde mejor aparece recogida la idea del castigo a la emisión indebida de un contaminante, en los términos del artículo $2^{\circ}$ de la Ley No. 19.300 ("todo elemento, compuesto, sustancia, derivado químico o biológico, energía, radiación, vibración, ruido, o una combinación de ellos, cuya presencia en el ambiente, en ciertos niveles, concentraciones o períodos de tiempo, pueda constituir un riesgo a la salud de las personas, a la calidad de vida de la población, a la preservación de la naturaleza o a la conservación del patrimonio ambiental”), pero únicamente referida a aquélla que pone en peligro la salud animal o vegetal o el abastecimiento de la población (de productos animales o vegetales, se entiende). Sin embargo, la falta de una clara identificación de los deberes jurídicos que debieran infringirse para cometer el delito, hacen de muy difícil aplicación práctica la fórmula utilizada por el legislador; ello, sin contar con la dificultad adicional de probar la propagación de tales sustancias y, sobre todo, su capacidad (una vez propagadas) para poner en peligro la salud animal o vegetal o el abastecimiento de la población.

Por otro lado, la fauna silvestre rara, protegida o en peligro de extinción encuentra una decidida protección penal, integrando al derecho nacio-

${ }^{28}$ También podrían entenderse como parte de la dispersa legislación protectora de los espacios naturales especialmente protegidos las normas de la Ley de Bosques, que se citan en el siguiente apartado. Cfr., con detalle, Castillo S., Marcelo: Régimen Jurídico de Protección del Medio Ambiente, 1994. 
nal las obligaciones contraídas en el tratado CITES, en los artículos 30 y 31 de la Ley de Caza, reformada íntegramente no hace mucho, donde se prohíbe la caza, captura y tráfico ilícito de tales especies. La Ley General de Pesca también ofrece una importante protección penal a las especies hidrobiológicas, castigando la pesca con artes prohibidos (artículo 135), la introducción ilegal de especies hidrobiológicas de carnadas no autorizadas (artículo 137), así como el procesamiento, elaboración o transformación de recursos hidrobiológicos vedados (artículo 139), disposición esta última de gran importancia como modelo de regulación, pues no sólo establece sanciones para personas jurídicas, sino que, además, hace directamente responsables de la falta que contiene a los gerentes o administradores de la industria donde ella se comete.

Por último, y en cuanto a la protección de la flora, nuestra ley se limita a un castigo genérico, a título de incendio, de la destrucción por esta vía de bosques, mieses, plantíos y montes, siempre que el delito se cometa dolosamente (artículo 476 N 3 del Código Penal) y culposamente sólo en los casos de roza a fuego con infracción de reglamentos (artículos 18 y 22 de la Ley de Bosques). Pero es lamentable que los reglamentos a que se refieren estas últimas disposiciones aún no han sido dictados. La misma Ley de Bosques contempla en su artículo 21 el delito de corte y tala ilegal de bosques y arbustos nativos; sin embargo, las limitaciones que se establecen para ese corte o tala están vinculadas más bien al aseguramiento de la mantención de los suelos y manantiales que a la protección de la masa arbórea, y siempre se permite solicitar al Servicio Agrícola y Ganadero una autorización para dicha tala o corte, con lo que la prohibición puede terminar siendo ilusoria.

e) Protección penal del medio ambiente frente a los peligros de las armas de destrucción masiva

Éste es otro aspecto de nuestra legislación en la materia que puede considerarse suficientemente regulado, atendido que, por una parte, la Ley de Seguridad Nuclear, № 18.302, castiga penalmente la realización sin autorización de actividades relativas a la energía y materiales nucleares (artículo 45); la causación dolosa o culposa de un “daño nuclear” (artículo 47); el peligro que para el ambiente importa el daño, ataque o sabotaje de instalaciones nucleares (artículo 41); el robo, hurto, sustracción o apropiación ilícita de materiales radiactivos (artículo 41 inc. $1^{\circ}$ ); el dar ocasión negligentemente al robo, hurto, sustracción o apropiación de dichos materiales (artículo 43 inc. $2^{\circ}$ ), y la amenaza condicional de causar un daño nuclear 
(artículo 46). Y por otra, la Ley No 17.798 sobre Control de Armas, prohíbe absolutamente la posesión de armas especiales, esto es, "las químicas, biológicas y nucleares” (artículo $3^{\circ}$ inc. 4), castigando con severas penas su porte y posesión (artículos $13^{\circ}$ y $14^{\circ}$ ) —sin ofrecer siquiera un régimen de permisos sobre ellas, como en el caso de las armas de fuego comunes-.

En resumen, a pesar de la no despreciable cantidad de las normas penales reseñadas (y de la relativa importancia de cada una de ellas), su carácter asistemático y de indirecta relación con el medio ambiente y sus componentes deriva a la postre en su insuficiencia para proteger adecuadamente dichos intereses, como veremos a continuación.

\section{La insuficiencia de la actual legislación penal ambiental chilena para una adecuada protección del medio ambiente y de la institucionalidad medioambiental}

\section{V.1. Insuficiencia de las disposiciones penales relativas al medio ambiente actualmente vigentes para cumplir con las obligaciones internacionales contraídas en la materia}

Revisado el actual estado de la legislación nacional relativa a la protección penal del medio ambiente, la primera conclusión que de ello resulta, la obvia inexistencia de una protección penal específicamente dirigida al medio ambiente o sus elementos, deja en entredicho el nivel de cumplimiento de las sugerencias que en esta materia se han realizado en el plano del derecho internacional. Pero también en particular, respecto de las materias en que específicamente los tratados suscritos por Chile imponen el establecimiento de delitos ambientales en la legislación nacional, una revisión del panorama legislativo nacional nos muestra serias insuficiencias, que es deber del Estado suplir.

En efecto, atendiendo el grado de cumplimiento de las obligaciones internacionales, podemos constatar lo siguiente:

a) que existe un pleno grado de cumplimiento respecto de la obligación de proteger penalmente el ambiente frente a los peligros de las armas de destrucción masiva, mediante las figuras penales contempladas en las leyes 18.314, Sobre Control de Armas, y 18.302, Sobre Seguridad Nuclear;

b) que similar grado de cumplimiento parece existir respecto de la protección penal de la biodiversidad y, en particular, de la fauna silvestre, a través de las disposiciones citadas en el apartado anterior, contempladas en el Código Penal, en la Ley General de Pesca y en la Ley de Caza, y 
c) que, en cambio, no existe una protección penal específica, en los términos a que obligan los tratados y convenios internacionales suscritos por Chile y que se encuentran vigentes, por no existir tipos penales específicos, o porque los existentes no permiten un adecuado grado de protección, en los términos de los tratados o convenciones, respecto de la protección penal del medio ambiente antártico (no existe legislación específica en la materia, y sólo podría aplicarse a su respecto el artículo 136 de la Ley General de Pesca, en cuanto se refiere a la contaminación de las aguas, pero con las importantes dificultades antes señaladas); del medio ambiente, y particularmente de los suelos, frente al tráfico ilícito de desechos peligrosos (un proyecto de ley que regulaba la materia —Boletín 150/11 — fue archivado recientemente en esta Cámara), y de las aguas, particularmente de las marinas (el D. L. 2.222, Ley de Navegación, entrega el control de la contaminación por hidrocarburos previsto en el Tratado MARPOL a la Dirección del Territorio Marítimo, estableciendo un régimen de sanciones administrativas solamente, mientras el —artículo 136 de la Ley General de Pesca presenta serias dificultades de aplicación, como ya se explicó).

\section{V.2. Insuficiencia de las disposiciones penales relativas al medio ambiente para la prevención de fenómenos de grave contaminación ambiental}

Salvo las disposiciones de difícil aplicación práctica relativas a la contaminación de aguas con venenos o productos infecciosos (artículo 315 del Código Penal) y a la introducción en ellas de agentes contaminantes “que causen daño a los recursos hidrobiológicos” (artículo 136 de la Ley General de Pesca), no existen en nuestro ordenamiento jurídico normas que, como las previstas en el derecho comparado, castiguen la grave contaminación (tanto dolosa como negligente) de los aires, las aguas y el suelo, ni tampoco los hechos que producen serios riesgos de contaminación, como los relativos al tráfico ilícito de desperdicios y sustancias altamente peligrosas para el medio ambiente y aun para la salud de las personas, originados tanto en el abuso de los permisos obtenidos mediante el Sistema de Evaluación de Impacto Ambiental como en la codicia o maldad humana, o incluso en la negligencia de quienes, realizando actividades o proyectos peligrosos para el medio ambiente, no ponen el debido cuidado que ello exige para impedir derrames de fluidos o sustancias que podrían dañar gravemente el medio ambiente y la vida y salud humana, animal y vegetal.

Sin embargo, también es cierto que resulta muy difícil la configuración de delitos de grave contaminación ambiental, tomando en cuenta la 
inexistencia actual de normas de emisión para todos los contaminantes ${ }^{29}$; la utilización de las existentes como instrumentos de gestión ambiental, que permiten el gradual acercamiento de las fuentes a los límites que se fijan para cada una de ellas, y sobre todo el carácter de dichas Normas de Emisión, cuyos límites máximos toman en cuenta objetivos relacionados con Normas de Calidad Ambiental, lo que supone considerar el efecto acumulativo de ciertas emisiones en determinados ámbitos territoriales, que por lo mismo no permite tomarlas en general como indicadores de la gravedad intrínseca de la emisión de contaminantes en cada fuente, individualmente considerada.

\section{V.3. Insuficiencia de los instrumentos jurídicos actualmente disponibles para la sanción de quienes burlan el Sistema de Evaluación de Impacto Ambiental}

Asumiendo que el Sistema de Evaluación de Impacto Ambiental previsto por la Ley $\mathrm{N}^{\circ} 19.300$ ha de constituir la base de la gestión ambiental nacional, si fijamos la atención en la necesaria protección que debiera dis-

${ }^{29}$ Actualmente se han dictado sólo las siguientes normas de emisión:

a) Respecto de contaminantes en el aire por fuentes móviles: D. S. No 104 de 2000 (Ministerio de Transportes y Telecomunicaciones), Norma de emisión para motocicletas; Decreto No 130 de 2002 (Ministerio de Transportes y Telecomunicaciones Subsecretaria de Transportes), Normas de emisión de Co, Hct, Hcnm, Ch4, Nox y material particulado para motores de buses de locomoción colectiva de la ciudad de Santiago; Decreto No 103 de 2000 (Ministerio de Transportes y Telecomunicaciones y Comisión Nacional del Medio Ambiente), Norma la emisión de hidrocarburos no metánicos para vehículos livianos y medianos; D. S. No 4 de 1994 (Ministerio de Transportes y Telecomunicaciones), Normas de emisión de contaminantes aplicables a los vehículos motorizados;

b) Respecto de la contaminación del aire por otras fuentes: D. S. No 167 de 1999 (Ministerio Secretaría General de la Presidencia), Norma de emisión para olores molestos; D.S. No 165 de 1999 (Ministerio Secretaría General de la Presidencia), Norma de emisión para la regulación del contaminante arsénico emitido al aire.

c) Respecto de la emisión de contaminantes en las aguas: D. S. № 90 de 2000 (Ministerio Secretaría General de la Presidencia), Norma de emisión para la regulación de contaminantes asociados a las descargas de residuos líquidos a aguas marinas y continentales superficiales; y D. S. 46 de 2002 (Ministerio Secretaría General de la Presidencia), Norma de emisión de residuos líquidos a aguas subterráneas.

d) Respecto de la emisión de contaminación lumínica en la II, III y IV Región: D. S. No 686 de 1998 (Ministerio de Economía, Fomento y Reconstrucción), Norma de emisión para la regulación de la contaminación lumínica;

e) Respecto de la contaminación por ruidos molestos: D. S. N 146 de 1997 (Ministerio Secretaría General de la Presidencia), Norma de emisión de ruidos molestos generados por fuentes fijas. 
pensarse al adecuado funcionamiento de la administración ambiental — como se dispensa por la vía penal en el sistema norteamericano-, para evitar su burla y descrédito consecuente (junto con los peligros o daños ambientales que de ello derivan), podemos hacer notar ciertas insuficiencias graves en la legislación ambiental, que no se encuentran en otros ámbitos de actividades especialmente reguladas.

Así, mientras en nuestra legislación se sanciona con las penas del perjurio a quienes presentan declaraciones juradas falsas para la realización de determinados trámites o la obtención de ciertas prestaciones ${ }^{30}$, quien presenta ante el Sistema de Evaluación de Impacto Ambiental una declaración jurada falsa sobre el impacto ambiental de su actividad o proyecto no está sujeto a ninguna sanción específica.

Lo mismo sucede con la presentación de antecedentes falsos o la omisión de otros verdaderos al presentar los correspondientes a un estudio de impacto ambiental, cuya falsedad u omisión no tienen una sanción penal, mientras que sí la tendrían si se tratase de antecedentes a presentar con relación a la mayor parte de las actividades sujetas al control estatal por medio de superintendencias u otros organismos de la administración ${ }^{31}$.

Tampoco existen específicas sanciones que castiguen a quienes — como lo hace el artículo 327 del Código Penal respecto de los peritos

${ }^{30}$ Ver al respecto: artículo 29 DL 1.305/1976 que reestructura y regionaliza el Ministerio de la Vivienda y Urbanismo; artículo 17 DL 1.939/1977; artículo $1^{\circ}$ Ley 18.270, Establece Normas para el Otorgamiento de Títulos Gratuitos de Dominio sobre Tierras Fiscales Rurales en la XI Región; artículo 11 inc. $4^{\circ}$ y 18 inc. $3^{\circ}$. Ley 18.883 , Aprueba Estatuto Administrativo de los Funcionarios Municipales; artículo 12 inc. $4^{\circ}$ y 17 inc. $3^{\circ}$. Ley 18.834, Estatuto Administrativo; artículo 6º Ley 19.360; artículo 18 Ley 18.603, Ley Orgánica Constitucional de Partidos Políticos; artículo 16 DL 539/1974, Establece Normas sobre Reajustabilidad y Pago de Dividendos de Deudas Habitacionales.

${ }^{31}$ Ver al respecto: artículo 70 Ley 16.741, Establece Normas para Saneamiento de los Títulos de Dominio y Urbanización de Poblaciones en Situación Irregular; artículo $1^{\circ}$ Ley 19.083, Establece Normas sobre Reprogramación de Deudas del Crédito Fiscal Universitario; artículo $6^{\circ}$ Ley 19.287, modifica Ley 18.591 y Establece Normas sobre Fondos Solidarios de Crédito Universitario; artículo 50 Ley 19.162, Establece Sistema Obligatorio de Clasificación de Ganado; artículo 37, inc. 2o. Ley 18.168 General de Telecomunicaciones; artículo 50 Ley 18.933, Crea la Superintendencia de Instituciones de Salud Previsional; artículo 49 DFL 251/1931, Sobre Compañías de Seguros, Sociedades Anónimas y Bolsas de Comercio; artículo 59, letras a) y f) Ley 18.045, Sobre Mercado de Valores; artículo 49 Ley 18.876, Establece el Marco Legal para la Constitución y Operación de Entidades Privadas de Depósito y Custodia de Valores; artículo 59 Ley 18.840 Orgánica Constitucional del Banco Central de Chile; artículo 19 bis Ley 18.902, Crea Superintendencia de Servicios Sanitarios; 158 DFL 3/1997 (Hacienda), Ley General de Bancos; artículo 8 DFL 15/1991 (Vivienda), Establece Normas sobre Deudores Habitacionales Ley 19.003; artículo 3ㅜ, Ley 19.353, Condona Deudas que Indica Derivadas del Proceso de Reforma Agraria. 
judiciales y otros funcionarios auxiliares de la justicia que emiten informes falsos-, en el proceso de Evaluación de Impacto Ambiental, emitan, a favor de terceros interesados, informes falsos o incompletos que influyan en la decisión de la comisión respectiva o que, interviniendo de cualquier manera en el proceso, oculten o adulteren información que deba tomar en cuenta el órgano resolutivo competente.

Por otra parte, una decidida protección del Sistema de Evaluación de Impacto Ambiental resultaría insuficiente y hasta inequitativa para quienes se someten a dicho sistema si no se establecen importantes estímulos coercitivos para quienes, debiendo someter sus actividades o proyectos a la aprobación de las comisiones pertinentes, simplemente pretenden "ahorrarse” el gasto asociado a dicha evaluación y, sin más, se ponen fuera de la regulación ambiental y desarrollan sus actividades o proyectos fuera de toda legalidad, tal como sucede actualmente con la instalación de vertederos de residuos sólidos clandestinos ${ }^{32}$. Así, resulta necesaria, junto con la protección en el orden penal del Sistema de Evaluación de Impacto Ambiental, la sanción también penal — que vaya más allá de la inaplicada y modesta pena de falta prevista en el artículo 495 Nº 9 para el que “abriere establecimientos sin licencia de la autoridad, cuando sea necesaria”- a quienes burlan derechamente dicho sistema y emprenden proyectos o actividades sin someterse a la evaluación ambiental, cuando ello es obligatorio, tal como hoy se castiga penalmente el desarrollo de ciertas actividades que, requiriendo un especial reconocimiento del Estado o el cumplimiento de ciertos requisitos legales, no lo tienen, como sucede con las universidades, la actividad bancaria y de seguros, etc. ${ }^{33}$.

${ }^{32}$ Materia que por su gravedad ha concitado la atención de los honorables señores diputados patrocinantes de las mociones sobre el proyecto de ley que establece penalidades a los vertederos clandestinos (Boletín 2401-12) y sobre el que prohíbe el traslado y posterior depósito de basuras y desperdicios generados en una región al territorio de otra (Boletín 2721-12).

${ }^{33}$ Ver al respecto: artículo 3 DL 3.631/1981, Fija Normas sobre Universidades; artículo 25 DL 3.500/1980, Establece Sistema de Pensiones; artículo 60 letras a), b) y c) Ley 18.045, Sobre Mercado de Valores; artículo 46 DFL 251/1931 Sobre Compañías de Seguros, Sociedades Anónimas y Bolsas de Comercio; artículo 48 DFL 251/1931 Sobre Compañías de Seguros, Sociedades Anónimas y Bolsas de Comercio; artículo 51 DFL 251/1931 Sobre Compañías de Seguros, Sociedades Anónimas y Bolsas de Comercio; artículo 39 DFL 3/1997 (Hacienda), Ley General de Bancos; artículo 23, incs. $1^{\circ}$ a $3^{\circ}$ Ley 18.933, Crea la Superintendencia de Instituciones de Salud Previsional; artículo 38 Ley 19.220, Regula Establecimientos de Bolsas de Productos Agropecuarios; artículo $8^{\circ}$ inc. $1^{\circ}$ Ley 19.491 Regula Funcionamiento de Administradoras de Recursos Financieros de Terceros Destinados a la Adquisición de Bienes; artículo 76 Ley 19.518, Fija Nuevo Estatuto de Capacitación y Empleo; artículo 30, incs. $5^{\circ}$ a $7^{\circ}$ Ley 19.728, Establece un 


\section{La insuficiencia de los proyectos legislativos en la materia. Reseña y análisis crítico}

Los más importantes proyectos de ley presentados en el Parlamento hasta ahora —y que se encuentran en actual tramitación_— ${ }^{34}$, referidos al establecimiento de una sanción penal para quienes dañan o ponen en grave peligro el medio ambiente o burlan el Sistema de Evaluación de Impacto Ambiental, se contienen en la moción parlamentaria de los diputados señores Aníbal Pérez, Juan Bustos, Luksic, Elgueta, Sánchez, Encina, Ojeda, José Pérez, Mora y Rincón sobre un proyecto de ley que tipifica el delito medioambiental (Boletín 2177-12), y en la moción de los diputados señores Gustavo Alessandri, Roberto Delmastro, Rafael Arratia, Alejandro Navarro, Mario Acuña y Leopoldo Sánchez sobre el proyecto de ley que establece penalidades a los vertederos clandestinos (Boletín 2401-12) ${ }^{35}$.

\section{VI.1. El proyecto de Ley que Tipifica el Delito Ambiental (Boletín 2177-12)}

Este proyecto de ley se fundamenta, según la moción que le dio origen $^{36}$, en la constatación de que "el proceso de deterioro de nuestro

Seguro de Desempleo; artículo 36 B, letra a), Ley 18.168 General de Telecomunicaciones; artículo 63 Ley 18.045, Sobre Mercado de Valores; artículo 196-A de la Ley de Tránsito $\mathrm{N}^{\circ}$ 18.290; artículo 23, incs. $1^{\circ}$ y $2^{\circ}$, Ley 18.118 Legisla Sobre el Ejercicio de la Actividad de Martillero Público; y artículo 495 Nº 9 del Código Penal.

${ }^{34}$ Lamentablemente, en la sesión $7^{\text {a }}$ de la $347^{a}$ Legislatura Ordinaria (13.06.2002), la importante, aunque insuficiente, moción sobre un proyecto de ley que prohibía el ingreso al territorio nacional de desechos provenientes de terceros países (Boletín No 150-11), fue archivada por la Cámara de Diputados en su tercer trámite constitucional, a sugerencia de la Comisión de Recursos Naturales, Bienes Nacionales y Medio Ambiente, donde se esgrimió que dichas conductas ya se encontraban reguladas en el Convenio de Basilea sobre el Control de los Movimientos Transfronterizos de los Desechos Peligrosos y su Eliminación, lo que si bien es cierto en cuanto obligación internacional (ver supra II), no lo es si la Cámara creyó que bastaría con la aprobación de dicha Convención para modificar la ley nacional y establecer delitos y penas, pues no son las convenciones internacionales fuentes del derecho penal interno, mucho menos cuando en ellas se establece la obligación de legislar, naturalmente, una vez que se haya aprobado el convenio que obliga en ese sentido.

${ }^{35}$ Además de las mociones citadas arriba en el texto, con especial incidencia en la penalización de conductas que afectan al medio ambiente, se encuentran en tramitación las mociones sobre el proyecto que prohíbe el traslado y posterior depósito de basuras y desperdicios generados en una región, hasta el territorio de otra (Boletín 2721-12), y un número importante de mociones sobre protección del medio ambiente desde diferentes puntos de vista (Boletines 2725-12, 2992-12, 2238-12, 2703-12, entre otros).

${ }^{36}$ Moción agregada a la cuenta de la Sesión $2^{\text {a }}$ de la Legislatura 338, de 3 de junio de 1998. 
medio ambiente constituye una realidad alarmante, que no muestra señales de detenerse o, al menos, de ir en un retroceso continuo que permitiera anticipar un futuro en el que fuera una realidad la garantía contemplada en el artículo $19 \mathrm{~N}^{\circ} 8^{\circ}$ de nuestra Constitución Política del Estado, esto es, el derecho a vivir en un medio ambiente libre de contaminación”, y de que "la necesidad de recurrir a normas penales protectoras de éste se debe a que la experiencia está cada día probando que la legislación civil y administrativa por sí sola ha demostrado ser muy ineficaz en su fuerza preventiva y protectora del medio ambiente", pues "la denominada "delincuencia ambiental" por las Naciones Unidas ha sabido sobrepasar sin problemas los obstáculos que tales leyes han impuesto”. A esta constatación se agrega que "en nuestra Ley sobre Bases Generales del Medio Ambiente se mantienen los principios clásicos de responsabilidad subjetiva civil en materia del daño al medio ambiente” y que, por tanto, “existe un gran vacío, pues esta ley apunta a la responsabilidad civil por el daño ambiental, pero no se tipifica el delito ecológico contra el medio ambiente como lo hacen otras leyes marco internacionales sobre el medio ambiente”.

Su texto contiene cuatro artículos, en el primero de los cuales se pretende tipificar el delito ambiental como una contravención grave a las normas de emisión y de calidad ambiental, y establecer las penas correspondientes, incluyendo entre ellas la clausura e intervención del establecimiento ${ }^{37}$, mientras en el segundo y el tercero se establecen las agravaciones por muerte o afección irreversible a la salud de las personas y destrucción irreversible del medio ambiente ${ }^{38}$; y en el cuarto, la aclaración de que estas

37 Artículo $1^{\circ}$. "El que contraviniendo gravemente las normas primarias de calidad ambiental que establecen los valores de las concentraciones y períodos máximos o mínimos permisibles de elementos, compuestos, sustancias, derivados químicos o biológicos, energías, radiaciones, vibraciones, ruidos o combinación de ellos, cuya presencia o carencia en el ambiente pueda constituir un riesgo para la vida o la salud de la población, será sancionado con la pena de presidio menor en su grado medio a máximo. Si la contravención de las normas constituye un riesgo para la protección o la conservación del medio ambiente, o la preservación de la naturaleza, la pena será de presidio menor en su grado mínimo a medio.

Si dichas violaciones se producen por negligencia grave, la pena se rebajará en un grado.

En caso de reincidencia, las penas anteriormente señaladas se aumentarán en un grado.

En los casos previstos en este artículo podrá acordarse la clausura temporal o definitiva del establecimiento, pudiendo además el Tribunal disponer la intervención de la empresa, para resguardar los derechos de los trabajadores.”

${ }^{38}$ Artículo $2^{\circ}$. "Si como consecuencia de las conductas penales descritas en el artículo anterior, se produjera, por imprudencia grave, la muerte de una persona o una 
sanciones son independientes de las civiles y administrativas que correspondan ${ }^{39}$.

En su primer trámite constitucional, el proyecto se ha discutido en la Comisión de Recursos Naturales, Bienes Nacionales y Medio Ambiente de la Cámara, donde se recibieron numerosas observaciones críticas, sin que hasta el momento se haya dado cuenta del informe de dicha Comisión ante la Cámara de Diputados.

La primera observación importante que puede hacerse a este proyecto es que el delito ambiental que se pretende tipificar en él parece reducirse únicamente a la sanción de ciertos supuestos de grave contaminación ambiental, dejando fuera de su alcance la protección del Sistema de Evaluación de Impacto Ambiental, por lo que resulta, por sí solo, insuficiente para la adecuada protección del medio ambiente, conforme con las obligaciones internacionales contraídas y la experiencia del derecho comparado.

Además, como se puso de relieve en la discusión habida en el seno de la Comisión, el proyecto parece adolecer de serias deficiencias técnicas, producto sin duda de las premuras legislativas más que de otra cosa. Así, entre los invitados a las discusiones hubo acuerdo en que no es posible castigar la infracción de normas de calidad ambiental, pues éstas no permiten ser “infringidas”, en términos de su sobrepasamiento por una fuente individual, porque ellas definen únicamente concentraciones máximas de contaminantes en territorios y épocas determinadas, por lo que únicamente podría hacerse una referencia a las normas de emisión, que sí tienen relación con fuentes individuales de contaminantes ${ }^{40}$. Pero aun en ese caso se puso de manifiesto que la sola infracción a las normas de emisión, cronogramas de reducción de emisiones, paralización o restricciones referidas a situaciones especiales de emergencia ambiental se encuentra sancionada hoy en día en el artículo 56 de la Ley 19.300, concluyendo que para “que el tipo penal propuesto sea una norma eficaz y eficiente requiere de ser adecuado a la

afección irreversible en su salud, la pena aplicable será la de presidio menor en su grado máximo a presidio mayor en su grado mínimo."

Artículo $3^{\circ}$. "Si como consecuencia de la contravención de las normas de calidad ambiental, la destrucción del medio ambiente es irrecuperable, la pena prescrita en el artículo $1^{\circ}$ será de presidio menor en su grado medio a máximo.”

${ }^{39}$ Artículo $4^{\circ}$. "Las penas contempladas en la presente ley se impondrán sin perjuicio de otras sanciones y reparaciones que contemple la legislación vigente para las conductas descritas en los artículos anteriores.”

${ }^{40}$ En este sentido se pronunciaron los señores Álvaro Sapag (director jurídico de Conama), Marcelo Castillo (experto invitado) y Claudio Osorio (abogado del Instituto de Libertad y Desarrollo), según consta en el borrador del Informe de la Comisión, que no ha sido ingresado todavía a la cuenta de la Cámara. 
normativa ambiental vigente»41. También se destacó que técnicamente el proyecto carecía de una descripción más o menos precisa de la conducta punible, pues si se saca la oración que continúa a posteriori de la frase “normas primarias de calidad ambiental”, se llega a la siguiente redacción: "El que contraviniendo gravemente normas primarias de calidad ambiental será sancionado con la pena de presidio menor en su grado medio a máximo”42. También se señaló que el proyecto, a pesar de contener sanciones para las personas jurídicas en su artículo $1^{\circ}, 43$ no parecía hacerse cargo cabalmente del problema de en qué casos dichas personas jurídicas serían sancionables, teniendo en cuenta que, conforme a nuestro sistema punitivo, en materia penal las personas jurídicas no responden criminalmente, sino sólo sus administradores ${ }^{44}$. Finalmente, se echó en falta la carencia de mecanismos normativos que incentivaran la reparación del daño ambiental causado $^{45}$.

\section{VI.2. El Proyecto de Ley que establece penalidades a los vertederos clandestinos (Boletín 2401-12)}

Este proyecto se encuentra algo más avanzado en su tramitación que el anterior, pues ya se ha dado cuenta ante la Cámara del correspondiente Informe de la Comisión de Recursos Naturales, Bienes Nacionales y Medio Ambiente (Sesión 35 a de la 342 ${ }^{\mathrm{a}}$ Legislatura, 6.09.2000).

Como se señala en la moción origen del proyecto, éste se fundamenta en que actualmente "las sanciones administrativas vigentes no resultan suficientes para disuadir a los que contravienen las normas sanitarias que regulan la puesta en marcha, operación o explotación de los vertederos o rellenos sanitarios”46, pues las multas contempladas en el artículo 174 del Código Sanitario (de una a 1.000 UTM) no han sido obstáculo para "la operación de vertederos o rellenos sanitarios ilegales” que “pone[n] en riesgo la salud de la población y el medio ambiente, especialmente en las grandes ciudades", ni mucho menos para frenar "la existencia de verdaderas asociaciones ilícitas que operan como mafias, en sitios eriazos, abandona-

\footnotetext{
${ }^{41}$ En este sentido se pronunciaron el señor Álvaro Sapag (director jurídico de Conama) y el diputado señor Juan Bustos.

${ }^{42}$ En este sentido se pronunció el señor Marcelo Castillo.

43 Ver nota 37.

${ }^{44}$ En este sentido se pronunciaron los señores Castillo y Osorio.

${ }^{45}$ En este sentido se pronunciaron el señor Osorio y el diputado señor Bustos.

${ }^{46}$ En el Informe de la Comisión se citan, en este mismo sentido, además, las opiniones del señor Marcel Zsantó, docente de la Universidad Católica de Valparaíso.
} 
dos o fuera de los límites de la ciudad, recibiendo todo tipo de basuras y desechos, sin ningún control por parte de las autoridades"47.

El proyecto propone la introducción de un artículo único en el Libro II, Título VI, Párrafo 14 “Crímenes y simples delitos contra la salud pública”, del Código Penal, ocupando el lugar del artículo 319 a), que fuera derogado por la ley $\mathrm{N}^{0} 17.934$, que creaba una figura penal que sancionaba a quien mantuviere, administrare, operare o explotare vertederos, depósitos de basura o rellenos sanitarios ilegales, y también a quien transporte, conduzca, traslade o deposite basuras, desechos o residuos en lugares clandestinos, agravándose las penas cuando las basuras o residuos fueren tóxicos, peligrosos, infecciosos, corrosivos, combustibles, inflamables o pusieren en grave peligro la salud de la población o el medio ambiente ${ }^{48}$.

Sin entrar en los detalles técnicos del proyecto, es claro que, si bien se mira, en él se está sancionando principalmente la infracción a la obligación que establece el artículo 10, letra O), de la Ley Nº 19.300, Ley de Bases del Medio Ambiente, que obliga a someter al Sistema de Evaluación de Impacto Ambiental los proyectos de saneamiento ambiental, tales como

${ }^{47}$ En el Informe de la Comisión, concordando con lo señalado en la moción, se agrega el siguiente dato que avala lo dicho arriba en el texto: "De acuerdo con información publicada por el diario 'El Mercurio', de fecha 25 de junio, el valor por camionada de residuos alcanza la suma de $\$ 4.000$. Es decir, por menos de $\$ 30.000$ una persona resuelve su problema de residuos sólidos. En cambio, si las mismas 10 toneladas son depositadas en un vertedero autorizado, la suma se eleva a \$ 46.600, sólo por dejarlos. La estimación publicada considera que la tonelada entregada a un depósito ilegal tiene un valor de entre \$ 1.800 y \$ 2.000 la tonelada, lo que explicaría la proliferación de los vertederos ilegales”. Además, según la información entregada a la Comisión por Juan Claudio Godoy, entonces presidente de Emeres, en 1994 existían en 101 vertederos indiscriminados de residuos sólidos en lugares no autorizados, de los cuales 78 se situaban en el área urbana y 23 en zonas rurales, con una superficie afectada de 713 hectáreas, y los residuos alcanzaban un volumen de 10 millones de metros cúbicos. Por su parte, el doctor José Concha, director del Servicio Metropolitano del Ambiente, informó que aunque en la prensa ha contabilizado 101 vertederos, en la práctica "el catastro que tiene Sesma y los que han sido objeto de sumarios, alcanzan a diecinueve", y que "las multas que al respecto establece el Código Sanitario, pueden aumentarse o duplicarse hasta el infinito, pero en la práctica no se cumplen, aun cuando también se puede decretar la clausura”.

${ }^{48}$ El proyecto quedó como sigue, después de su discusión en la Comisión:

“Artículo Único. Intercálase un nuevo artículo 319 al Código Penal.

"Artículo 319. El que mantuviere, administrare, operare o explotare vertederos, depósitos de basura o rellenos sanitarios ilegales, será sancionado con presidio menor en sus grados mínimo a medio.

"En la misma sanción incurrirá el que transporte, manipule, conduzca, traslade o deposite basuras, desechos o residuos en dichos lugares.

"Si las basuras, residuos o desechos fueren tóxicos, peligrosos, infecciosos, corrosivos, combustibles, inflamables o pusieren en grave riesgo la salud de la población o el medio ambiente, la pena podrá elevarse en uno o dos grados”. 
plantas de tratamiento de residuos sólidos, de origen domiciliario, rellenos sanitarios, sistemas de tratamiento y disposición de residuos industriales.

De allí que, aunque nada parece aconsejar dejar de castigar penalmente esta burla al Sistema de Evaluación de Impacto Ambiental, ello parece muy insuficiente en orden a una protección moderna y adecuada a los requerimientos de la comunidad internacional y las experiencias del derecho comparado, pues la pregunta que surge inmediatamente es si no sería preferible una disposición que abarcara en general la infracción al deber impuesto por la Ley 19.300, de someter al Sistema de Evaluación de Impacto Ambiental todas las actividades que señala en sus artículos 10 y 11, incluyendo naturalmente la actividad a que se refiere el proyecto, pero sin excluir las restantes actividades que allí se enumeran - letras a) a q) del artículo 10 -, precisamente por el impacto negativo que ellas producen o pueden producir en el medio ambiente ${ }^{49}$.

Estas insuficiencias del proyecto parecen haber hecho fuerza en la Sala de la Cámara al momento de su votación, pues no se aceptó su tramitación como proyecto de fácil despacho, quedando hasta la fecha a la espera de ser puesto en la tabla ordinaria (Sesión $37^{\mathrm{a}}$ de la $342^{\mathrm{a}}$ Legislatura, 12.09.2000) $)^{50}$.

${ }^{49}$ En un sentido similar se manifestó ante la Comisión el señor Eduardo Correa, representante de Conama Región Metropolitana, pues aunque rechazó en particular el texto del Proyecto, pues entiende más eficaces otras vías de protección diferentes a la penal, afirmó que si se seguía esta última sería preferible "pensar en la creación de otras figuras penales, como pudieran ser la contaminación de aguas, vertimiento de contaminantes atmosféricos o incluso la creación de un delito ecológico". También opinó en contra del proyecto el doctor Concha, director del Sesma Metropolitano, a pesar de reconocer la ineficacia de las sanciones administrativas que muchas veces no pueden siquiera notificarse o se dirigen a personas distintas de los operadores de los vertederos clandestinos. Sin embargo, es importante destacar el apoyo de los representantes de Hidronor, señores Pierre Servanti y José Javier Irureta, a la idea de imponer sanciones ejemplificadoras en esta materia, como un mecanismo de protección de las cuantiosas inversiones que realizan los operadores de vertederos legales.

${ }^{50}$ El parecer de la Sala se refleja en la opinión expresada por el diputado señor Víctor Pérez, quien solicitando se estudie más detenidamente la materia, fundamenta esta petición con la pregunta acerca de "si el proyecto en discusión resuelve el problema [de los basurales clandestinos]”, pues, en consonancia con la opinión del diputado señor Navarro, afirma "que aquí estamos atacando sólo una parte —me temo que muy pequeña_ de las dificultades ocasionadas por los basurales clandestinos, mediante el establecimiento de una figura penal: a quien tenga un vertedero o traslade basura se le aplicará una determinada sanción”. Añade que la figura propuesta, por una parte, deja fuera situaciones como la autorización indebida de los mismos (cita el ejemplo del basural en la comuna de Cabrero, autorizado por el Servicio de Salud de esa provincia, pero no por la Comisión Regional del Medio Ambiente); y por otra, como señaló también el diputado señor Exequiel Silva, la figura penal afecta del mismo modo al propietario del predio en el que se 


\section{Conclusión: la necesidad de un nuevo derecho penal ambiental chileno. Ideas matrices del proyecto que se propone}

\section{VII.1. La necesidad de un nuevo derecho penal ambiental chileno. Fundamentos de la propuesta al Foro Penal}

La preocupación por los peligros que para el medio ambiente y la salud de las personas de las actuales y futuras generaciones representan ciertas actividades de gran potencial contaminador propias de nuestro estadio de desarrollo económico y social, sumada a la existencia de concretas obligaciones en materia de derecho penal medioambiental ${ }^{51}$, la ya decantada práctica y doctrina en el derecho comparado acerca de la necesidad de regular penalmente los atentados al medio ambiente, y las insuficiencias en la regulación penal de la materia en el derecho nacional, justifican con creces las iniciativas parlamentarias que, desde diferentes puntos de vista, han propuesto establecer sanciones propiamente penales a quienes realizan hechos que podemos caracterizar como de grave contaminación ambiental (o peligro de la misma), como es el caso de la recién analizada moción sobre un proyecto de ley que tipifica el delito medioambiental (Boletín 2177-12); o de burla del Sistema de Evaluación Ambiental, como en el caso particular de la también ya revisada moción sobre el proyecto de ley que establece penalidades a los vertederos clandestinos (Boletín 2401-12) ${ }^{52}$. Sin embargo, como acabamos de demostrar, dichas iniciativas son, también, insuficientes para una adecuada y moderna protección, en sede penal, del medio ambiente.

deposita basura, a los dueños de los camiones que transportan residuos en forma ilegal y a las personas naturales que depositan una bolsa, un cajón o cualquier desecho en un vertedero ilegal, por lo que "al no existir una graduación, es decir, al no haber distintas penas, ocurrirá lo que siempre sucede en nuestros tribunales de justicia: los jueces evitarán aplicar sanciones, porque éstas pueden resultar desproporcionadas”; y además no señala una autoridad encargada de la acción penal en estos casos, pues "se sabe que cuando todos pueden iniciar una acción penal, al final nadie lo hace, porque no entregamos a una autoridad la facultad de representar a la comunidad".

${ }^{51}$ Cfr. al respecto, Lizaur G. Margallo, Helena: "El Delito Ecológico en España”, 2000, pp. 41 y ss., quien reseña además los condicionamientos propios del sistema de la Unión Europea que hacen inevitable esta clase de regulación. En todo caso, las disputas de competencia entre los órganos de la Unión Europea, han retrasado hasta la fecha la adopción de una decisión vinculante para sus miembros, como puede verse en las informaciones relativas a la actual propuesta de la Comisión Europea sobre una "Directiva Relativa a la Protección del Medio Ambiente por medio del Derecho Penal” (COM (2007) 51), no publicada todavía en el Diario Oficial, pero disponible, junto con la información a que se hace referencia, en http://europa.eu/scadplus/leg/es/lvb/l28189.htm [visitado el 19.06.2008].

${ }^{52} \mathrm{Cfr}$. Apartado VI de este trabajo. 
Atendido la anterior, sostiene la Secretaría Técnica de la Comisión Foro Penal en los Materiales de Estudio de la Unidad 4 (Parte especial) lo mismo que sostuviéramos en el Informe Final del Proyecto Fondecyt que sirvió de base para la propuesta de regulación:

Los problemas normativos en esta materia no parecen, por tanto, referidos a la discusión acerca del "si" de la protección penal del medio ambiente, sino más bien a la pregunta respecto del "cómo" ha de establecerse esta regulación, en un sistema de derecho penal heredero en cierta medida del espíritu de la ilustración liberal ${ }^{53}$. Por ello, la regulación propuesta limita el castigo penal a graves y fácilmente comprobables actos de contaminación (daño ambiental, en los términos de la Ley $\mathrm{N}^{\circ} 19.300$ ) o peligro de ella, de modo que la ley se haga al mismo tiempo aprehensible para el ciudadano común e impida que una simple autorización dada por organismos o funcionarios administrativos elimine la tipicidad de la figura penal, no atribuyéndose al mismo tiempo la imposible tarea de prevenir todos los atentados al ambiente, sino la más modesta de aplicar un castigo proporcional y racional a quien ha puesto gravemente en peligro la comunidad o ha causado una grave contaminación. Esta forma de abordar la materia permite, además, excluir del ámbito de lo punible la contaminación de bagatela, producto de la actividad diaria de todos y cada uno de los habitantes de la República, cuyo control, naturalmente, sólo puede estar entregado a las disposiciones de carácter administrativo, como sucede paradigmáticamente con las emisiones de fuentes móviles (automóviles y similares) y fijas domésticas (chimeneas, etc.), que se excluyen derechamente de la sanción penal en el texto del que aquí proponemos.

Sin embargo, una legislación penal ambiental moderna no sólo debe asumir el desafío de adecuar su estructura al sistema administrativo de protección ambiental, sino además sortear las críticas y dificultades que otras legislaciones en la materia han padecido, concentradas sobre todo en los delitos que castigan la contaminación, pues en cuanto a los que se refieren a la protección de la administración (declaraciones falsas, emprender actividades sin autorización, etc.), existe en Chile una larga tradición normativa

${ }^{53}$ En este mismo sentido, cfr. Lira de Carvalho, Iván: "Direito Penal Mínimo, Eximentes e Dirimentes nos Crimes Ambientais”, 1997, pp. 16 y s. En Chile, el reclamo doctrinal en este sentido lo podemos encontrar ya desde el año 1993, en el artículo de Sharp V., Peter: “La Necesidad de un Derecho Penal Ecológico”, 1993, pp. 86 y ss. 
que jamás ha sido objeto de críticas como las vertidas contra los "modernos” delitos ecológicos.

Así, en cuanto a la supuesta indeterminación que tendría un derecho penal ambiental vinculado a los conceptos del derecho administrativo, desde luego, dicha indeterminación no se produce cuando la remisión se hace a conceptos claramente definidos en las leyes, como "Sistema de Evaluación de Impacto Ambiental”, “fuentes de emisión”, “biodiversidad”, etc. (artículo $2^{\circ}$. Ley 19.300), técnica de frecuente uso en el derecho penal vigente (así, el $\mathrm{N}^{0} 1$ del artículo 470 no sólo se refiere a contratos civiles —depósito, consignación, etc.- , sino que incluso somete su prueba a las reglas del derecho civil). Pero tampoco se produce per se cuando la remisión se hace a una norma de carácter reglamentario, pues tal como lo ha resuelto nuestro Tribunal Constitucional (Causa Rol No 4), una ley penal en blanco no es contraria a la garantía del principio de legalidad, siempre que el núcleo esencial de la conducta punible se encuentre descrito en la ley, como sucede paradigmáticamente en la Ley 20.000, Sobre Tráfico Ilícito de Estupefacientes.

Tampoco parece de recibo, a priori, la crítica contra el establecimiento de delitos de peligro en esta materia, pues, en primer lugar, no está puesta en duda seriamente la constitucionalidad de los delitos de peligro, sino sólo su conveniencia. Y es un hecho que, tratándose de determinadas materias donde no resulta en absoluto conveniente esperar el resultado lesivo para su castigo penal, la vía adecuada es el establecimiento de delitos de peligro, tal como sucede con los delitos relativos a la salud pública, i. e. envenenamiento de aguas o diseminación de gérmenes patógenos (de los artículos 315 y 316 del Código Penal), respecto de los cuales la producción de resultados lesivos para la vida o la salud de personas determinadas opera sólo como agravante de la figura de peligro básica.

También los problemas prácticos derivados de la prueba del peligro, sobre todo en la comprobación de si un suceso determinado puede calificarse o no de grave contaminación, pueden sortearse mediante la técnica de la ley penal en blanco, del mismo modo que actualmente la Ley 20.000 hace respecto de las sustancias estupefacientes o sicotrópicas capaces de causar o no graves daños a la salud de las personas; y mediante la determinación precisa, por un reglamento destinado exclusivamente al efecto, de las cantidades de emisiones o sustancias capaces de producir grave contaminación ambiental.

De esta manera, limitando el castigo penal a graves y fácilmente comprobables actos de contaminación o peligro de ella, la ley se hace aprehensible para el ciudadano común e impide que una simple autorización dada por organismos o funcionarios administrativos elimine la tipicidad de 
la figura penal, no atribuyéndose al mismo tiempo la imposible tarea de prevenir todos los atentados al ambiente, sino la más modesta de aplicar un castigo proporcional y racional a quien ha puesto gravemente en peligro la comunidad o ha causado una grave contaminación. Esta forma de abordar la materia permitiría, además, excluir del ámbito de lo punible la contaminación de bagatela, producto de la actividad diaria de todos y cada uno de los habitantes de la República, cuyo control, naturalmente, sólo puede estar entregado a las disposiciones de carácter administrativo, como sucede paradigmáticamente con las emisiones de fuentes móviles (automóviles y similares) y fijas domésticas (chimeneas, etc.), que se excluyen derechamente de la sanción penal en el texto del proyecto de ley que aquí proponemos.

Y ante la crítica de una cierta ineficacia del derecho penal ambiental para prevenir y castigar sucesos de gran contaminación ${ }^{54}$, de entrada puede replicarse que lo mismo habría que criticar al derecho administrativo ambiental ${ }^{55}$, y que, por tanto, ello no se opone seriamente a la "unánime opinión que considera imprescindible una protección penal del medio ambiente más extensa y eficaz”56. Además, no deja de ser cierto que esas críticas provienen en España de la defectuosa técnica legislativa que allí se emplea (la indeterminada remisión a las "normas generales reguladoras del medio ambiente") ${ }^{57}$, y en Alemania de las orientaciones de los órganos de persecución, donde en la práctica los procesos parecen haberse dirigido más hacia delitos de bagatela ${ }^{58}$ que contra los "grandes" agentes contaminadores, y el recurso a la exclusión de la pena (abstención de condena) ha provocado muy dispares sentencias ${ }^{59}$. En este aspecto, es importante destacar la perspectiva pragmática de la experiencia norteamericana donde, junto con hacer hincapié en la protección penal del sistema administrativo de gestión ambiental mediante la tipificación de delitos formales de muy larga tradición

${ }^{54}$ Crítica que muy claramente expresó, en la discusión en el seno de la Comisión de Recursos Naturales, Bienes Nacionales y Medio Ambiente, sobre el proyecto de ley que tipifica el delito ambiental, el representante del Instituto Libertad y desarrollo, abogado Claudio Osorio (Boletín 2177-12).

${ }^{55} \mathrm{Al}$ respecto es ilustrativa la ineficacia del SESMA en el control de los vertederos clandestinos, tal como su propio director, el doctor Concha, lo reconoce, según recoge el Informe de la Comisión de Recursos Naturales, Bienes Nacionales y Medio Ambiente (Sesión 35a de la 342 ${ }^{\mathrm{a}}$ Legislatura, 6.09.2000).

${ }^{56}$ Vega Ruiz, José Augusto: Delitos contra el Medio ambiente, Ordenación del Territorio, Patrimonio Histórico, Flora y Fauna en el Código Penal de 1995, 1996.

${ }^{57}$ En palabras de Rodríguez Devesa refiriéndose al anterior artículo 347 bis: "no se hubiera hecho mejor si, deliberadamente, se hubiese buscado la más absoluta ineficacia" (Rodríguez Devesa y Serrano: Derecho Penal español, Parte Especial, 1994, p. 1109).

${ }^{58}$ Cramer: "Comentarios a los Artículos 324ss del Código Penal”, 1997, p. 2178.

${ }^{59}$ Rangier, Rudolf: Strafrecht, Besonderer Teil II, 1999, p. 306. 
jurídica (presentación de documentos falsos, etc.), para una adecuada persecución de los delitos de peligro de contaminación o de grave contaminación se han tomado seriamente en cuenta las necesidades logísticas que requiere un programa criminal ambiental exitoso, particularmente en el ámbito de la investigación y el análisis de evidencia, donde la capacidad instalada en personal y laboratorios especializados se ha mostrado imprescindible para la prueba del hecho punible.

\section{VII.2. Ideas matrices del texto aprobado por la Comisión Foro Penal}

Bien jurídico protegido: El proyecto propone proteger penalmente el medio ambiente, entendido como "el sistema global constituido por elementos naturales y artificiales de naturaleza física, química o biológica, socioculturales y sus interacciones, en permanente modificación por la acción humana o natural y que rige y condiciona la existencia y desarrollo de la vida en sus múltiples manifestaciones” (artículo 2 letra ll) de la Ley 19.300); directamente, a través de los delitos dolosos y culposos de grave contaminación o peligro de la misma (artículos 167 y 168); e indirectamente, a través de los delitos de realización sin autorización de las actividades sujetas al Sistema de Evaluación de Impacto Ambiental (art. 170) y de tráfico no autorizado de sustancias tóxicas o peligrosas (art. 171).

Producto de la sistemática general del Anteproyecto de Código Penal, las otras formas de protección del sistema de administración ambiental, esto es, el castigo penal de la presentación de declaraciones juradas falsas o documentos falsos o incompletos, omisión de presentación de antecedentes imprescindibles en el proceso de Evaluación de Impacto Ambiental, evacuación de informes periciales u oficiales falsos, y otorgamiento de autorizaciones indebidas en el proceso de Evaluación de Impacto Ambiental, quedan comprendidas en las reglas generales que para el castigo de esas conductas se establecen en los delitos funcionarios y contra la administración del anteproyecto (perjurio, art. 288; delitos contra la fiscalización administrativa de mercados especialmente regulados, arts. 350 y 351; y prevaricación administrativa, art. 276).

Técnica legal empleada: Respecto de los delitos de contaminación o peligro de grave contaminación, se emplea la técnica de la ley penal en blanco, en el sentido autorizado por el Tribunal Constitucional, con referencia a un reglamento específico que debe dictarse en la materia — siguiendo el modelo de la Ley 20.000_-, el que sólo podrá considerar constitutiva de 
un "grave daño ambiental”, "la emisión de sustancias contaminantes en cantidades y proporciones significativamente superiores a los máximos señalados en las normas de emisión que sean aplicables” (Art. 172). Esto significa que la comunidad deberá acordar cuánta contaminación acepta y cuál es el límite entre la simple contaminación (infracción administrativa) y grave daño ambiental. Se espera que por la naturaleza de la reglamentación, ésta se someta al mismo procedimiento de discusión pública de las Normas de Calidad y Emisión actualmente vigentes.

Delitos de resultado, de peligro y de mera actividad: Los delitos que contempla el articulado propuesto atienden en su estructura al objeto de protección, de manera que no siguen una única línea en esta materia. Así, mientras los delitos de grave contaminación de los artículos 167 y 168 por su naturaleza son delitos de resultado, se prevén no obstante reglas especiales para determinar cuándo se producen los resultados que se pretenden evitar, vinculados a pruebas objetivas de cantidades de emisiones y de relación causal (artículos 172 y 232 del anteproyecto), facilitando así la acción de los órganos encargados de hacer cumplir la ley. Lógicamente, también se prevé el castigo de la producción, transporte y almacenamiento no autorizado de ciertas sustancias contaminantes particularmente peligrosas para el medio ambiente, respecto de las cuales no resulta adecuado esperar que causen efectivamente un grave daño ambiental para ser punibles (artículo 171). Aquí, como en muchos delitos contra la salud pública, se impone la necesidad de establecer una figura de peligro, cuyo ámbito de punibilidad se limita por la exigencia de que las sustancias y cantidades de las mismas deben estar fijadas previamente por el reglamento a que ya se ha aludido. Por otra parte, en los delitos relativos a la protección del Sistema de Evaluación Ambiental se mantiene la técnica tradicional en esta clase de delitos vinculados a la protección de la administración, consistente en figuras de mera actividad (art. 170).

Delitos dolosos y culposos: Los delitos que establece el proyecto de ley son, por regla general dolosos y permiten tanto la imputación a título de dolo directo como de dolo eventual, evitando utilizar expresiones como "maliciosamente" o "con conocimiento de causa” u otras similares que podrían llevar a interpretar la exclusión del castigo a título de dolo eventual. Sólo respecto del delito de grave contaminación se establece el correspondiente delito culposo, atendido que es posible apreciar un resultado materialmente constatable, y que en tales casos es precisamente la culpa por 
negligencia o infracción de reglamentos la que produce los “accidentes” ambientales de mayor magnitud (artículo 168).

Responsabilidad de los administradores: El proyecto, consciente de que la mayor parte de los delitos ambientales contemplados en él se cometen en el ámbito de una organización empresarial, y profundizando la senda iniciada por los artículos 136 y 139 de la Ley General de Pesca, pone en primera línea de imputación a los gerentes, directores y administradores a cualquier título del proyecto o actividad donde se origina la fuente de emisión de contaminantes o que están obligados a someterse al Sistema de Evaluación de Impacto Ambiental. Sólo se permite la excepción de responsabilidad de los directivos a cargo cuando es posible demostrar su oposición a los hechos constitutivos de delito, acciones de sabotaje u otra intervención de tercero imposible de controlar por los mecanismos internos de la empresa (artículo 228 del anteproyecto).

Responsabilidad de las personas jurídicas: En esta materia, el proyecto no innova respecto de las reglas generales de nuestro ordenamiento, pero establece un régimen paralelo de sanciones de carácter administrativo, aplicadas por el tribunal que conoce del delito ambiental respectivo, consistente en fuertes multas, clausuras temporales o definitivas en caso de reincidencia, y la inscripción en un sistema de registro público que ha de tomarse en cuenta a la hora de evaluar nuevos proyecto o actividades de la persona jurídica sancionada (artículo 229).

Cuantía de las multas: Siguiendo la tradición jurídica reflejada en el artículo 501 del Código Penal, según la cual en las mismas materias las sanciones administrativas no pueden ser de mayor entidad que las penales, la cuantía de las multas que se establecen en el proyecto propuesto pretendían ser superiores a las que pueden imponerse por la administración en materias similares. Sin embargo, no en todos los casos se logró esa pretensión y, en lo que a mi juicio es la deficiencia más notable de la regulación de cuantías que se propuso al Foro Penal (y ello, independientemente de los cambios operados en las mismas), se echa en falta un análisis económico que permita efectivamente hacer de las multas un instrumento disuasorio de los hechos cuya comisión se pretende evitar, y no un "incentivo perverso" a costear dentro de los cálculos financieros de los destinatarios de la norma. 
Modificaciones estructurales: Por la naturaleza del anteproyecto de Código Penal, no fue posible introducir las normas relativas a las necesarias modificaciones estructurales que permitirían una eficaz persecución de esta clase de delitos, como sería la creación de un Comité Operativo al alero de la Comisión Nacional del Medio Ambiente, en conformidad al artículo 77 de la Ley 19.300, que, sin tener como función el ejercicio de la acción penal, colabore activamente en la investigación de los delitos contemplados en el proyecto, y que, para lograr una adecuada coordinación con los organismos encargados de la persecución penal de los delitos de carácter ambiental, esté integrado necesariamente con personas provenientes del Consejo de Defensa del Estado, del Ministerio Público y de profesionales provenientes de las universidades del Estado, expertos en ciencias de la naturaleza y que cuenten con laboratorios para la realización de los análisis y peritajes que sean pertinentes.

No obstante, se agrega en las Disposiciones comunes del Título de delitos de peligro común, donde se encuentran los relativos al medio ambiente, una regla que facilita la prueba de la relación causal entre la contaminación y los daños causados, según el modelo de causalidad estadística (artículo 232 del anteproyecto), salvando de este modo las importantes dificultades habidas en la experiencia comparada respecto a esta prueba.

\section{VII.3. Texto aprobado por la Comisión Foro Penal}

\section{TÍTULO IX \\ DELITOS DE PELIGRO COMÚN}

\section{$\S 1$. Delitos relativos al medio ambiente}

Art. 167. El responsable o administrador de un proyecto o actividad que en su operación produzca un grave daño ambiental, será castigado con la pena de reclusión menor en su grado medio y multa de dos mil a tres mil unidades tributarias mensuales.

La pena será el máximum de la señalada en el inciso anterior y multa de tres mil a cinco mil unidades tributarias mensuales, si el grave daño ambiental a que se refiere el inciso anterior pone en serio peligro la vida o la salud de personas determinadas.

Si el grave daño ambiental produce lesiones de las contempladas en los artículos 85 y 87 № 2 de este código a una o más personas, se 
aplicará la pena de reclusión menor en su grado máximo y multa de cuatro mil a cinco mil unidades tributarias mensuales.

La pena será de reclusión menor en su grado máximo a mayor en su grado mínimo y multa de cinco mil a siete mil unidades tributarias si las lesiones producidas son las del No 1 del artículo 87.

Si el grave daño ambiental produce la muerte de una o más personas, la pena será de reclusión mayor en sus grados mínimo a medio y multa de siete mil a diez mil unidades tributarias mensuales.

Art. 168. El responsable o administrador de un proyecto o actividad que por imprudencia en su operación produzca un grave daño ambiental, será castigado con la pena de reclusión menor en su grado mínimo y multa de dos mil a cuatro mil unidades tributarias mensuales.

La pena corporal será de reclusión menor en su grado mínimo a medio si el grave daño ambiental pone en peligro la vida o la salud de personas determinadas; y de reclusión menor en su grado medio, si produce alguna de las lesiones de los artículos 85 y 87 a una o más personas. Si el grave daño ambiental produce la muerte de una o más personas, la pena corporal será de reclusión menor en su grado máximo a mayor en su grado mínimo. En todos los casos en que del grave daño ambiental se deriven lesiones o muertes, la pena pecuniaria no podrá ser inferior a tres mil unidades tributarias mensuales.

Art. 169. Las mismas penas señaladas en el artículo anterior se impondrán a los responsables o administradores de un proyecto o actividad que contando con una autorización o certificación ambiental para su operación, produzcan un grave daño ambiental por el incumplimiento de las condiciones o exigencias bajo las cuales se les otorgó la certificación y los permisos correspondientes o que pongan en serio peligro la vida o la salud de una o más personas determinadas o les provoquen lesiones o muerte, sin perjuicio de las responsabilidades y sanciones administrativas correspondientes.

Art. 170. El responsable o administrador de un proyecto o actividad que conforme a la Ley deba someterse al sistema de evaluación de impacto ambiental, lo ejecute o mande a ejecutar sin hacerlo previamente, será castigado con una multa de mil a tres mil unidades tributarias mensuales, sin perjuicio de las penas que correspondan por la comisión de alguno de los delitos descritos en los artículos anteriores.

La misma pena se impondrá al responsable o administrador de un proyecto o actividad que, habiéndose sometido al sistema de evalua- 
ción de impacto ambiental, lo ejecute o mande a ejecutar en términos diversos a los que fueron aprobados o autorizados.

Art. 171. El administrador o responsable de un proyecto o actividad que sin la competente autorización extraiga, produzca, transforme, transporte, distribuya, venda, compre, importe o exporte, guarde o almacene sustancias tóxicas o peligrosas en cantidades tales que constituyan un serio peligro de grave daño ambiental, será castigado con la pena de reclusión menor en su grado mínimo y multa de tres mil a cinco mil unidades tributarias mensuales.

Si el peligro a que se refiere el inciso anterior incluyese un serio riesgo para la salud o la vida de personas determinadas, la pena será de reclusión menor en su grado medio y multa de tres mil a cinco mil unidades tributarias mensuales.

Las mismas penas se impondrán al responsable o administrador de un proyecto o actividad que, habiendo obtenido la autorización a que se refiere el inciso primero, incumpla sus condiciones u obligaciones.

Art. 172. Un reglamento determinará las sustancias y cantidades o proporciones de contaminantes provenientes de una misma fuente emisora cuya emisión al medio ambiente constituya un grave daño ambiental en los términos descritos en los artículos 167 y 168, y las que, en su caso, pongan en serio peligro la vida y la salud de personas determinadas expuestas a él.

Este reglamento sólo podrá considerar como constitutiva de un grave daño ambiental, la emisión de sustancias contaminantes en cantidades o proporciones significativamente superiores a los máximos señalados en las Normas de Emisión que sean aplicables.

El reglamento también determinará las cantidades de las sustancias tóxicas o peligrosas a que se refiere el artículo 171 respecto de las cuales las conductas allí señaladas constituyan un serio peligro de grave daño ambiental, y las que, en su caso, constituyan un serio riesgo para la vida y la salud de personas determinadas.

Art. 173. Las disposiciones de los artículos precedentes no serán aplicables a las emisiones provenientes de vehículos sujetos a inscripción en el Registro Nacional de Vehículos Motorizados, chimeneas y demás sistemas de calefacción o refrigeración domésticos, las que, en caso de exceder las Normas de Emisión correspondientes, se regirán por las disposiciones generales aplicables en la materia. 


\section{§ 9. Disposiciones comunes}

Art. 228. Para los efectos de lo dispuesto en este Título, se entenderán como responsables o administradores de una empresa, proyecto o actividad los que lo sean de hecho o de derecho y, especialmente, sus representantes, directores y gerentes.

Respecto de estas personas, y sin perjuicio de las reglas generales, se estimará suficiente prueba para eximirlas de responsabilidad penal por alguna de las conductas sancionadas en este Título, la de haberse opuesto al acto u omisión que constituye el delito, intentando seriamente evitar su realización; o mediante el establecimiento previo de medidas de control administrativo que sus subordinados hubiesen infringido, sin su conocimiento o sin que les fuese posible evitarlo, por provenir de acciones de sabotaje u otras intervenciones de terceros de similares características.

En el caso de los directores o gerentes de una persona jurídica, su oposición al acto que constituye el delito, podrá acreditarse con la sola exhibición de las actas correspondientes a la sesión del directorio en que se decidió su realización.

En caso de sabotaje o intervención de terceros de similares características, se sancionará con las mismas penas previstas para los responsables o administradores de la empresa, proyecto o actividad, a quienes lo sean del sabotaje o la intervención de que se trate.

Art. 229. Las personas jurídicas cuyos responsables o administradores sean condenados por alguno de los delitos previstos en este Título, serán sancionadas por el Tribunal que conozca de dicho delito, sin perjuicio de las sanciones civiles y administrativas correspondientes, con una o más de las siguientes medidas:

a) Multa de entre trescientas a quince mil Unidades Tributarias Mensuales, de acuerdo a la gravedad de la infracción y al patrimonio de la empresa sancionada;

b) Revocación de las autorizaciones infringidas; o

c) Clausura definitiva del proyecto o empresa en que incide el delito.

En todo caso deberá decretarse además la inscripción de la sanción en un registro público especial que llevará la Contraloría General de la República. Un reglamento regulará las formalidades de este registro, cuyas inscripciones deberán ser tomadas en cuenta para evaluar la seriedad de las garantías de los proyectos o empresas sujetos por el Estado a concurso público o privado. 
Las medidas señaladas en este artículo sólo se aplicarán cuando los delitos cometidos consistan en la infracción de un deber impuesto a la persona jurídica en el desarrollo del proyecto o actividad de que se trate, o cuando de su ejecución derive o pueda derivar un beneficio patrimonial para la empresa sancionada.

Art. 230. Las multas impuestas por la comisión de alguno de los delitos de este Título, o en virtud de lo dispuesto en el artículo anterior, podrán compensarse con los gastos que voluntaria y efectivamente se hubieran realizado para eliminar el peligro creado por el delito, reparar el daño producido o indemnizar a las personas afectadas, cuando corresponda.

Art. 231. Sin perjuicio de lo dispuesto en los artículos tercero y cuarto de este Código, la aprobación por parte de la autoridad administrativa de una empresa o actividad contra lo dispuesto expresamente en la ley o los reglamentos aplicables, no exime de la responsabilidad penal y sólo podrá considerase como circunstancia atenuante en la comisión de los delitos contemplados en este Título, a menos de probarse que el responsable de los mismos hubiere obtenido dicha aprobación en connivencia con los funcionarios que indebidamente la otorgaron.

Art. 232. Sin perjuicio de las reglas generales, podrá tenerse por probado que la operación de un proyecto o actividad ha producido efectivamente lesiones graves o la muerte de una o más personas determinadas, si se cumplen los siguientes requisitos:

a) Que exista prueba de que una o varias personas determinadas estuvieron expuestas al peligro producido por el proyecto o actividad, con anterioridad a sus lesiones o muerte;

b) Que exista prueba pericial que aporte una explicación general sobre los procesos biológicos, químicos o físicos que desencadena en las personas la exposición al peligro de que se trate; y

c) Que exista prueba pericial de que en las personas lesionadas o muertas se desencadenaron similares procesos a los mencionados en la letra anterior, después de su exposición al peligro de que se trate.

Art. 233. Para los efectos de lo dispuesto en este Título, las expresiones técnicas se entenderán en el sentido de lo dispuesto en las leyes especiales y reglamentos aplicables. 


\section{REFERENCIAS BIBLIOGRÁFICAS}

Allendes, Marcia: “Obligaciones Internacionales de Establecer Delitos Medioambientales, Contempladas en los Tratados No Suscritos por Chile, Recopilación de Tratados Internacionales". Memoria para obtener el grado de Licenciada en Ciencias Jurídicas y Sociales de la Universidad de Talca, 2003.

Bascuñán Muñoz, Juan Francisco: Jurisprudencia de la Contraloría General de la República Relativa al Sistema de Evaluación de Impacto Ambiental: 19972000. Santiago: Conama, 2001.

Birnie, Patricia W. y Alan Boyle: Basic Documents on International Law and the Environment. Oxford University Press, 1995.

Brandariz García, José Ángel: "Cuestiones Derivadas de la Concurrencia del Derecho Penal y del Derecho Administrativo en Materia de Tutela del Medio Ambiente”. Presentado en el Seminario Internacional sobre Derecho Penal del Medio Ambiente, desarrollado en las ciudades de Talca y Curanipe, del 7 al 10 de octubre de 2002, en el marco del Proyecto Fondecyt 1010206-2001, dirigido por Jean Pierre Matus A.

Cámara de Diputados: Boletín. Varios números.

Cámara de Diputados, Comisión de Recursos Naturales, Bienes Nacionales y Medio Ambiente: Acta discusiones sobre la moción que tipifica el delito ambiental. Boletín No 2177-12.

Castillo S., Marcelo: Régimen Jurídico de Protección del Medio Ambiente. Santiago: BLOC, $2^{\text {a }}$ ed., 1994.

Castillo S., Marcelo, Jean Pierre Matus Acuña y María Cecilia Ramírez Guzmán: "Informe sobre el Derecho Penal Ambiental en el Derecho Comparado de Tradición Continental”. En Gaceta Jurídica, Vol. 260 (2002).

CITES Secretariat: Resolutions of the Conference of the Parties to CITES in Effect after the 11th Meeting. CITES Châtelaine-Genève 2000.

Comisión Europea: "Propuesta de Directiva Relativa a la Protección del Medio Ambiente por medio del Derecho Penal”. (COM (2007) 51). En http://eur-lex.europa.eu/ smartapi/cgi/sga_doc?smartapi!celexplus!prod!DocNumber\&lg=es\&type_doc= COMfinal\&an_doc $=2007 \&$ nu_doc $=51$.

Comisión Nacional del Medio Ambiente (Conama): Gestión Ambiental del Gobierno de Chile. Santiago: Conama, 1997.

Cramer, Peter: "Comentarios a los Artículos 324ss del Código Penal”. En Schönke y Schröder (eds), Strafgestzbuch Kommentar, 25. Ed. München 1997.

El Mercurio: de 4 de mayo de 2002, Cuerpo C. Crónicas, 9 de noviembre de 2002, Cuerpo C.

Emol: Crónica sobre hundimiento del buque petrolero Prestige y el posterior derrame de su cargamento en las costas gallegas. 30 de noviembre de 2002. http:// www.emol.com/noticias/internacional/detalle/detallenoticias.asp?idnoticia=99595.

Faraldo Cabana, Patricia: "Autoría Mediata con Aparatos Organizados de Poder en el Ámbito Empresarial”. Presentado en el Seminario Internacional sobre Derecho Penal del Medio Ambiente, desarrollado en las ciudades de Talca y Curanipe, del 7 al 10 de octubre de 2002, en el marco del Proyecto Fondecyt 1010206-2001, dirigido por Jean Pierre Matus A. 
Fischer, Thomas: Strafgesetzbuch und Nebengesetze. München: C. H. Beck, 55 ed., 2008. Fuentes Olivares, Flavio: Manual de Derecho Ambiental. Valparaíso: Libromar, 1999.

Geisse G., Guillermo: 10 Años de Debate Ambiental. Santiago, Editorial Ambiente y Desarrollo, 1993.

Godoy, Juan Claudio: Declaraciones ante la Comisión de Recursos Naturales, Bienes Nacionales y Medio Ambiente de la Cámara de Diputados (Sesión 35 de la 342 ${ }^{\mathrm{a}}$ Legislatura, 5.09.2000).

González Campos, Julio D., Luis I. Sánchez Rodríguez y Paz Andrés Sáenz de Santa María: Curso de Derecho Internacional Público. Madrid: Civitas, 2a. ed. rev. 1998.

Hajek, Ernst, Guillermo Espinoza y Patricio Gross: Percepción de los Problemas Ambientales en las Regiones de Chile. Santiago 1994.

Huerta Tocildo, Susana: "Principios Básicos del Derecho Penal y Artículo 325 del Código Penal”. En Revista Penal, 8 (2001), 39-52.

La Tercera: Editorial de 14 de febrero de 2002.

Leme Machado, Paulo Affonso: Direito Ambiental Brasileiro. São Paulo: Malheiros Editores, $5^{\text {a }}$ edición, 1992.

Libster, Mauricio H.: Delitos Ecológicos. Buenos Aires: Depalma, 2a ed., 2000.

Lira de Carvalho, Iván: "Direito Penal Mínimo, Eximentes e Dirimentes nos Crimes Ambientais". En Enfoque Jurídico, enero/febrero 1997.

Lizaur G. Margallo, Helena: "El Delito Ecológico en España”. En Revista Jurídica Universitaria Interamericana de Puerto Rico, Vol. XXXV, № 1 (2000), 39-53.

Llanos Mansilla, Hugo: La protección Jurídica del Medio Ambiente en Chile: Convenios Internacionales. Red Internacional del Libro, 1955.

Matus, J. P. (ed.): Derecho Penal del Medio Ambiente. Santiago: Ed. Jurídica, 2004.

Matus A., Jean Pierre y Marcos Orellana C.: "Acerca de la Existencia de Obligaciones Internacionales de Establecer Delitos Medioambientales, Contempladas en los Tratados Suscritos por la República de Chile”. En Revista de Derecho y Jurisprudencia, Tomo XCVIII, № 4, 2001.

Ministerio de Economía, Fomento y Reconstrucción (Gobierno de Chile): D. S. No 686 de 1998. Norma de emisión para la regulación de la contaminación lumínica.

Ministerio de Transportes y Telecomunicaciones (Gobierno de Chile): D. S. No 4 de 1994. Normas de emisión de contaminantes aplicables a los vehículos motorizados. D. S. No 104 de 2000. Norma de emisión para motocicletas.

- Subsecretaria de Transportes (Gobierno de Chile): Decreto No 130 de 2002. Normas de emisión de Co, Hct, Hcnm, Ch4, Nox y material particulado para motores de buses de locomoción colectiva en la ciudad de Santiago.

Ministerio de Transportes y Telecomunicaciones (Gobierno de Chile) y Comisión Nacional del Medio Ambiente (Gobierno de Chile): Decreto No 103 de 2000. Norma la emisión hidrocarburos no metánicos para vehículos livianos y medianos.

Ministerio Secretaría General de la Presidencia (Gobierno de Chile): D. S. No 146 de 1997. Norma de emisión de ruidos molestos generados por fuentes fijas.

D. S. N ${ }^{\circ} 165$ de 1999. Norma de emisión para la regulación del contaminante arsénico emitido al aire.

D. S. N ${ }^{\circ} 167$ de 1999. Norma de emisión para olores molestos.

D. S. No 90 de 2000. Norma de emisión para la regulación de contaminantes asociados a las descargas de residuos líquidos a aguas marinas y continentales superficiales. 
D. S. 46 de 2002. Norma de emisión de residuos líquidos a aguas subterráneas.

Montenegro, Sergio, Domique Hervé y Valentina Durán: Los Tratados Ambientales: Principios y Aplicación en Chile. Santiago: Conama, 2001.

ONU: Informe. Noveno Congreso de las Naciones Unidas Sobre Prevención del delito y Tratamiento del Delincuente. El Cairo, 29 de abril a 8 de mayo de 1995 (A/ CONF.169/16, 352-361).

Orellana C., Marcos: “Derecho Penal Ambiental en la Tradición del Common Law”. En Revista Chilena de Derecho, Vol. 29, № 2, 2002.

PNUMA: Derecho Internacional Ambiental Regional. México: PNUMA, 1993.

Puente Aba, Luz María: “La Reparación en el Marco del Derecho Penal Medioambiental”. Presentado en el Seminario Internacional sobre Derecho Penal del Medio Ambiente, desarrollado en las ciudades de Talca y Curanipe, del 7 al 10 de octubre de 2002, en el marco del Proyecto Fondecyt 1010206-2001, dirigido por Jean Pierre Matus A.

Rangier, Rudolf: Strafrecht, Besonderer Teil II. München: C. H. Beck, 2ª ed., 1999.

Reunión del Grupo Especial de Expertos sobre las Formas más Eficaces de Cooperación Internacional contra la Delincuencia Transnacional: Informe. Viena, diciembre 1993 (E/CN.4/1994/4/Add.2,10).

Rodríguez Devesa, José María y Alfonso Serrano: Derecho Penal Español, Parte Especial. Madrid: Dykison, $17^{\mathrm{a}}$ ed., 1994.

Schroeder, C.: "Cool Analysis Versus Moral Outrage in the Development of Federal Environmental Criminal Law”, En Wm. \& Mary L. Rev, 35 (1993).

Sharp V., Peter: "La Necesidad de un Derecho Penal Ecológico”. En Revista de Derecho, Universidad de Concepción, julio-diciembre de 1993.

Tiedemann, Klaus: Lecciones de Derecho Penal Económico (Comunitario, Español, Alemán). Barcelona: PVU, 1993.

Toledo Tapia, Fernando: Ley 19.300, sobre Bases Generales del Medio Ambiente, Historia Fidedigna y Concordancias Internas. Santiago: Conama, 1996.

Troncoso, Rodrigo y Scarlett Quiroga: “Análisis de los Delitos de Carácter Ambiental Contenidos en el Código Penal y en las Leyes Especiales Chilenas”. Memoria para obtener el grado de Licenciado en Ciencias Jurídicas y Sociales de la Universidad de Talca, 2002.

Valeije Álvarez, Inma: “Cuestiones Dogmáticas sobre el Delito de Contaminación Ambiental en el Artículo 325 del Código Penal Español”. Presentado en el Seminario Internacional sobre Derecho Penal del Medio Ambiente, desarrollado en las ciudades de Talca y Curanipe, del 7 al 10 de octubre de 2002, en el marco del Proyecto Fondecyt 1010206-2001, dirigido por Jean Pierre Matus A.

Vega Ruiz, José Augusto: Delitos contra el Medio Ambiente, Ordenación del Territorio, Patrimonio Histórico, Flora y Fauna en el Código Penal de 1995. Madrid: COLEX, 1996.

Vercher Noguera, Antonio: "Reflexiones sobre las Emisiones y Vertidos en los Delitos contra el Medio Ambiente y Algunos Aspectos Determinantes en los Mismos”. En Revista Penal, 7 (2001), 99-108.

Wrann, Andrés, Marcelo Andía y Gustavo Lagos: "Riesgo y Costo Social del Transporte de Sustancias Peligrosas en la Minería”. Centro de Investigación MineroMetalúrgico y Pontificia Universidad Católica de Chile, Informe de Avance, mayo 2000, en http://www.cipma.cl/hyperforum/chile1.doc. 